\title{
Fluorescence studies on the interaction between pyrene-labelled poly(acrylic acid) and cyclodextrins
}

\author{
J Sérgio Seixas de Melo, ${ }^{1 *}$ Telma Costa, ${ }^{1}$ Noémia Oliveira ${ }^{1}$ and Karin Schillén ${ }^{2}$ \\ ${ }^{1}$ Departamento de Química da Universidade de Coimbra, Rua Larga, 3004-535 Coimbra, Portugal \\ ${ }^{2}$ Physical Chemistry 1, Center for Chemistry and Chemical Engineering, Lund University, PO Box 124, SE-221 00 Lund, Sweden
}

\begin{abstract}
The interactions, in aqueous media, between a pyrene-labelled polyelectrolyte poly(acrylic acid) (PAAMePy) with two different degrees of labelling and $\beta$ - and $\gamma$-cyclodextrins $(\beta$ - and $\gamma$-CD) were studied using absorption and fluorescence (steady-state and time-resolved) techniques. In addition to qualitative and quantitative parameters obtained from absorption and steady-state fluorescence spectra, time-resolved fluorescence data are presented, allowing additional important observations regarding the nature of the interactions. From the overall data it was possible to conclude that in the case of interaction with $\gamma$-CD the efficient encapsulation of two pyrene units into the cavity of the cyclodextrin molecule leads to a decrease in the number of available free monomers and an increase in the number of preformed ground-state dimers (GSDs) of pyrene. It was also shown that contrary to the situation in water, where only intramolecular interactions are present, the addition of $\gamma$-CD leads to new interpolymeric interactions. The absence of significant changes is noted when the interactions of PAAMePy polymers take place with $\beta$-CD. The excimer-to-monomer fluorescence intensity ratio $\left(I_{E} / I_{M}\right)$ was found to increase with the added amount of $\gamma$-CD but not with $\beta$-CD. This increase is justified on the basis of the increase of the GSD contribution. The photophysical behaviour was found to be dependent on the pH of the media, but with the absence of relevant interactions between $C D$ and PAAMePy polymer at alkaline values. (C) 2007 Society of Chemical Industry
\end{abstract}

Keywords: polymer photophysics; cyclodextrins; fluorescence; poly(acrylic acid); pyrene; excimer

\section{INTRODUCTION}

Studies of polymers modified with aromatic probes have gained an increased interest due to the possibility of following conformational properties at a molecular level. To follow these processes, fluorescence techniques are probably one of the most popular tools because they can directly and indirectly provide information concerning events occurring in a very short timescale. Poly(acrylic acid) (PAA) is an example of a charged polymer of particular interest, essentially because it is water soluble. The grafting of pyrene onto these polymers (PAAMePy) leads to a polymer that joins two characteristics: PAA with fluorescent probes. PAA has thus been hydrophobically modified by randomly attaching pyrene chromophores onto the polymer backbone. ${ }^{1-3}$ A comprehensive study of the photophysical behaviour of PAAMePy55 using steadystate and time-resolved fluorescence spectroscopy was previously undertaken. ${ }^{1}$ There, it was shown that the polymer conformation in water changes from compact at low $\mathrm{pH}$, to an open polymer coil at higher $\mathrm{pH}$, whereas the polymers are in an extended state when in dioxane and methanol. ${ }^{1}$ These studies have been extended to PAA labelled with naphthalene in water and organic solvent:water mixtures. ${ }^{4,5}$
Several organic molecules form inclusion complexes with torroidal-type molecules designated as cyclodextrins (CD) ${ }^{6-8}$ These consist of cyclic oligosaccharides with a hydrophobic cavity and hydrophilic outside due to their primary and secondary hydroxylic groups. ${ }^{9}$ The three most commonly studied members of the CD family are composed of 6,7 or 8 units of glucanopiranose and denominated as $\alpha$-, $\beta$ - and $\gamma$-cyclodextrin, respectively (see Scheme 1). They possess hydrophobic cavities of different inner diameter that ranges from 4.5 to $10 \AA$ ( $4.5-6.0 \AA$ for $\alpha-C D, 6.0-8.0 \AA$ for $\beta-C D$ and $8.0-10.0 \AA$ for $\gamma-C D) .{ }^{10,11}$ This hydrophobicity enables the cavity to include hydrophobic molecules such as pyrene ${ }^{7,12-15}$, naphthalene ${ }^{16}$ and several other compounds such as molybdenium, ${ }^{17}$ ferrocene-like complexes $^{18}$ and drugs. ${ }^{6,8}$ An interest exists in the pharmaceutical field in particular in the interactions of anti-inflammatory drugs and $\beta$-CD. ${ }^{19,20}$

The inclusion of guest molecules into the host cavity of the $\mathrm{CD}$ is driven, among others, by the hydrophobic character, shape and size of the cavities as well as the dispersion forces between the host and guest molecules. ${ }^{9}$ The interest in the host-guest relationship of these complexes lies in the fact that they possess a large field of actual and potential applications. \footnotetext{
E-mail: sseixas@ci.uc.pt

Contract/grant sponsor: Portuguese Science Foundation; contract/grant number: POCI/QUI/55672/2004

Contract/grant sponsor: FCT; contract/grant number: SFRH/BD/17852/2004

(Received 29 August 2006; revised version received 17 October 2006; accepted 3 November 2006)

Published online 12 January 2007; DOI: 10.1002/pi.2219
}

* Correspondence to: J Sérgio Seixas de Melo, Departamento de Química da Universidade de Coimbra, Rua Larga, $3004-535$ Coimbra, Portugal 


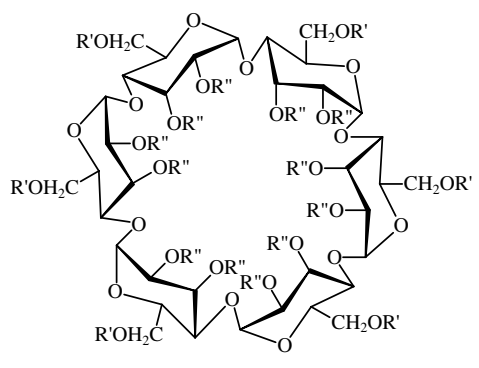

$\alpha$

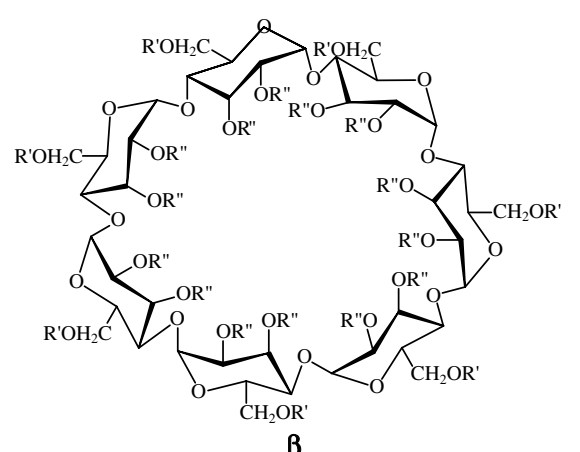

$\beta$

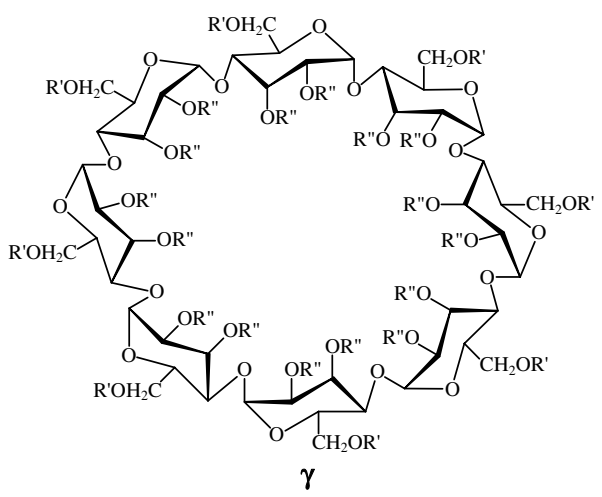

Scheme 1. Generic structures (top view) of $\alpha-, \beta$ - and $\gamma$-CD.

For example, they can increase the solubility of organic compounds in water; they can produce better analytical separation through the formation of host-guest complexes between the analyte and the $\mathrm{CD}$; and they are used for drug inclusion as a way to better deliver these. ${ }^{9,21}$ Examples of this are the non-steroidal anti-inflammatory drug nimesulfidecyclodextrin, whose formulations are commercially available, resulting in a faster action of its analgesic action. ${ }^{19}$ One limitation to its more widespread use lies in its poor solubility in water, which for $\beta$-CD is found to be $0.014-0.016 \mathrm{~mol} \mathrm{~L}^{-1}{ }^{7}$ However, this can be enhanced by methylation of the $\mathrm{OH}$ groups.

In the case of the pyrene molecule it is known that inclusion into the inner cavity of CD occurs and this can be followed by the promoted changes in its fluorescence spectra $\left(I_{\mathrm{E}} / I_{\mathrm{M}}\right.$ ratio) and lifetimes. ${ }^{7,2-15}$ In fact, the pyrene molecules form a 1:1 inclusion complex with cycloheptaamilose $(\beta-\mathrm{CD})$ that only displays the monomer pyrene fluorescence, whereas in the case of $\gamma$-CD (which possesses a larger inner cavity diameter) two pyrene units are able to go inside the $\mathrm{CD}$ cavity forming a $1: 2(\gamma-\mathrm{CD} /$ pyrene $)$ inclusion complex with consequent excimer emission. ${ }^{10,14,15,21}$ So far, no interaction studies have been carried out on dye-labelled polymers and CD. However, systems with CD-polymers and hydrophobically modified polymers $^{15,22}$ or free pyrene ${ }^{23}$, respectively, have been investigated. Other orders of complexes (for example a 2:2 complex) between $\gamma$-CD and pyrene-labelled polymers are not likely to occur since the interaction on one side is hindered by the PAA backbone.

The interaction between CD and hydrophobically modified polymers in water is therefore an important phenomenon since it provides a way of decreasing the viscosity of the solution. ${ }^{24}$ In this paper we present a comprehensive photophysical study of the kind and level of interactions between pyrene-labelled PAAMePy and $\beta$ - and $\gamma$-CD.

\section{EXPERIMENTAL Materials}

The polymers were synthesized by Dan Anghel in Lund (Physical Chemistry 1 laboratories during 1998

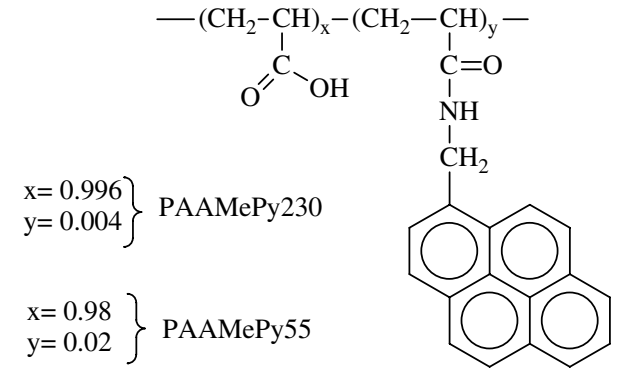

Scheme 2. Relative compositions (PAA versus pyrene unimer units) of polymers used and their corresponding abbreviations.

and 1999) and the synthesis followed the same route as previously described ${ }^{1,3,25}$ resulting in two pyrene (Py)-labelled PAA samples: one with a higher and one with a lower number of pyrene groups. The PAA polymer has a nominal molecular weight of $150000 \mathrm{~g}$ $\mathrm{mol}^{-1}$. All chemicals used in the syntheses were of reagent grade. 1-Pyrenylmethylamine hydrochloride, 1,3-dicyclohexylcarbodiimide and anhydrous 1-methylpyrrolidone were received from Aldrich Chemicals. Spectrum Medical Industries supplied the dialysis membranes with a molecular weight cut-off of $12000-14000 \mathrm{~g} \mathrm{~mol}^{-1}$. The amounts of pyrene were determined both by ultraviolet (UV) absorption measurements using 1-pyrenylmethylamine hydrochloride as a model compound and by ${ }^{1} \mathrm{H}$ NMR measurements in deuterium oxide. The pyrene content of the low-labelled PAA polymer was determined to $[\mathrm{Py}]_{\mathrm{Uv}}=0.43 \mathrm{~mol} \%$ (or $6.0 \times$ $10^{-5} \mathrm{~mol}\left(\mathrm{~g} \mathrm{polymer}^{-1}\right)$ and $[\mathrm{Py}]_{\mathrm{NMR}}=0.44 \mathrm{~mol} \%$ (or $6.1 \times 10^{-5} \mathrm{~mol}\left(\mathrm{~g}\right.$ polymer) $\left.{ }^{-1}\right)$. This corresponds to 230 (UV) or 227 (NMR) unimer units per chromophore, or 9 chromophores per polymer chain. This sample is therefore denoted PAAMePy230 (see Scheme 2). ${ }^{1}$ The pyrene content obtained for the second labelled PAA polymer was $[\mathrm{Py}]_{\mathrm{Uv}}=1.82 \mathrm{~mol} \% \quad\left(2.5 \times 10^{-4} \mathrm{~mol}(\mathrm{~g} \text { polymer })^{-1}\right)$ and $\quad[\mathrm{Py}]_{\mathrm{NMR}}=2.05 \mathrm{~mol} \% \quad\left(2.9 \times 10^{-4} \mathrm{~mol}\right.$ (g polymer) $)^{-1}$ ), which corresponds to 55 and 49 unimer units per chromophore or 38 and 43 chromophores per polymer chain, respectively. This sample is therefore denoted PAAMePy55 (see Scheme 2$)^{1}$ 
The $\beta$-CD (Fluka) and $\gamma$-CD (Aldrich) were used as received.

The solvents used in the polymer solutions were of spectroscopic or equivalent grade. Water was twice distilled and passed through a Millipore apparatus. The measured $\mathrm{pH}$ values were obtained with a Crison micropH 2000 and adjustments of the hydrogen ion concentration of the solutions were made with diluted $\mathrm{HCl}$ and $\mathrm{NaOH}$ solutions. The chromophore concentration of the aqueous PAAMePy solutions used in all fluorescence experiments ranged from $1 \times 10^{-5}$ to $10^{-6} \mathrm{~mol} \mathrm{~L}^{-1}$. Prior to experiments, they were deoxygenated by bubbling with nitrogen or argon and sealed. ${ }^{26}$ For this molecular weight, the polymer concentration in the different solutions was $0.05 \mathrm{~g} \mathrm{~L}^{-1}$, which is well below the critical value for coil overlap, $c^{*}$, and intermolecular chain contacts are therefore improbable in homogeneous solutions. The optical density of all solutions investigated was low and selfabsorption or inner filter effects were consequently prevented.

\section{Instrumentation}

Absorption and fluorescence spectra were recorded using Shimadzu UV-2100 and Horiba Jobin-Ivon SPEX Fluorog 3-22 spectrometers. All the fluorescence spectra were corrected for the wavelength response of the system.

Fluorescence decays were measured using a homebuilt ${ }^{27}$ TCSPC apparatus with a nitrogen-filled IBH 5000 coaxial flashlamp as excitation source, JobinIvon monochromator, Philips XP2020Q photomultiplier and Canberra instruments TAC and MCA. Alternate measurements (1000 c.p.c.) of the pulse profile at 316,335 or $355 \mathrm{~nm}$ and the sample emission were performed until $10^{4}-2 \times 10^{4}$ counts at the maximum were reached. Alternatively, as excitation source, a Horiba-JI-IBH NanoLED, $\lambda_{\mathrm{exc}}=339 \mathrm{~nm}$, was also used. The fluorescence decays were analysed using the modulating functions method of Stricker et al. ${ }^{28}$

Temperature control was achieved using a homebuilt system based on cooled nitrogen and electric heating, automatically controlled by the difference between the input temperature and the sample real temperature, determined with a PT100 thermometer.

The results from steady-state fluorescence experiments are presented as emission and excitation spectra but often also in terms of the ratio $I_{\mathrm{E}} / I_{\mathrm{M}}$ (ratio of the excimer-to-monomer bands). The $I_{\mathrm{E}} / I_{\mathrm{M}}$ ratio results from the decomposed area under the monomer and excimer bands. The general procedure to obtain those values consists in matching the emission spectra of pyrene in dioxane (with a concentration lower than $10^{-5} \mathrm{~mol} \mathrm{~L}^{-1}$ ) with the monomer band of the polymer. Since energetic differences exist between spectra of pyrene and the polymer, the match of the two implies a red shift of pyrene monomer; after this procedure, the relative intensities and vibronic band progression is almost identical for both compounds (polymer and pyrene). The resulting differential spectrum is the excimer emission band. In this procedure the $x x^{\prime}$-scale must be used in energy units (wavenumbers). ${ }^{1}$

\section{RESULTS AND DISCUSSION PAAMePy in water}

It was previously shown ${ }^{1}$ that the absorption and fluorescence (emission and excitation) spectra of pyrene-modified PAA are strongly dependent on the degree of pyrene label, $\mathrm{pH}$ and solvent media. By additionally using time-resolved fluorescence data it was possible to establish that these changes were dependent on the fraction of isolated pyrene chromophores and on the level of ground-state association, i.e. ground-state dimers (GSDs). ${ }^{1}$

Figure 1 illustrates, in a summarized form, the above mentioned effects of the degree of labelling in the absorption and fluorescence spectra of PAAMePy polymers. More details can be found in Seixas de Melo et al. ${ }^{1}$ Moreover the interactions are purely intramolecular as discussed in Appendix A (see Fig. A1) where it is observed that for different polymer concentrations (change by a factor of five) there is no change in the monomer-to-excimer emission ratio and thus no interpolymeric interactions are likely to be present. Evidence for the absence of interpolymeric interactions in analogous polymers has been shown in previous works. ${ }^{5,29}$ In fact, with identical naphthalene-labelled PAA polymers, it is shown that intermolecular interactions become important only above $10 \mathrm{~g} \mathrm{~L}^{-1}{ }^{29}$ This was also shown for PAAMePy polymers. ${ }^{3}$

\section{Addition of $\gamma$-CD to aqueous solution of PAAMePy}

Absorption spectra

When $\gamma$-CD is added to the aqueous solution of each of the two polymers (PAAMePy55 and PAAMePy230), there is a dramatic change in the absorption spectra at $\mathrm{pH} 3$, whereas almost no change is observed at $\mathrm{pH}$. The absorption spectra in Fig. 2 illustrate this behaviour for the two pyrene-labelled polymers.

The data in Fig. 2 were obtained for fixed concentrations of the polymers and varying the concentration of $\gamma-\mathrm{CD}$. At $\mathrm{pH}=3$, there is a clear increase in the bandwidth between 350 and $400 \mathrm{~nm}$. Concomitantly there is also an increase in the second vibronic peak with increasing amount of added $\gamma-$ CD.

The interior of a CD molecule appears nonpolar relative to the surrounding water. It is well known that free pyrene can form inclusion complexes with different $\mathrm{CD}$ due to the hydrophobic interaction. ${ }^{10}$ The cavity of $\gamma$-CD can accommodate up to two free pyrene molecules. ${ }^{10}$ In the case of pyrene groups attached to a polymer chain, such as PAA, it is likely that they prefer to form inclusion complexes with $\mathrm{CD}$ to avoid unnecessary exposure to water. We also suggest that each pair of pyrene chromophores 

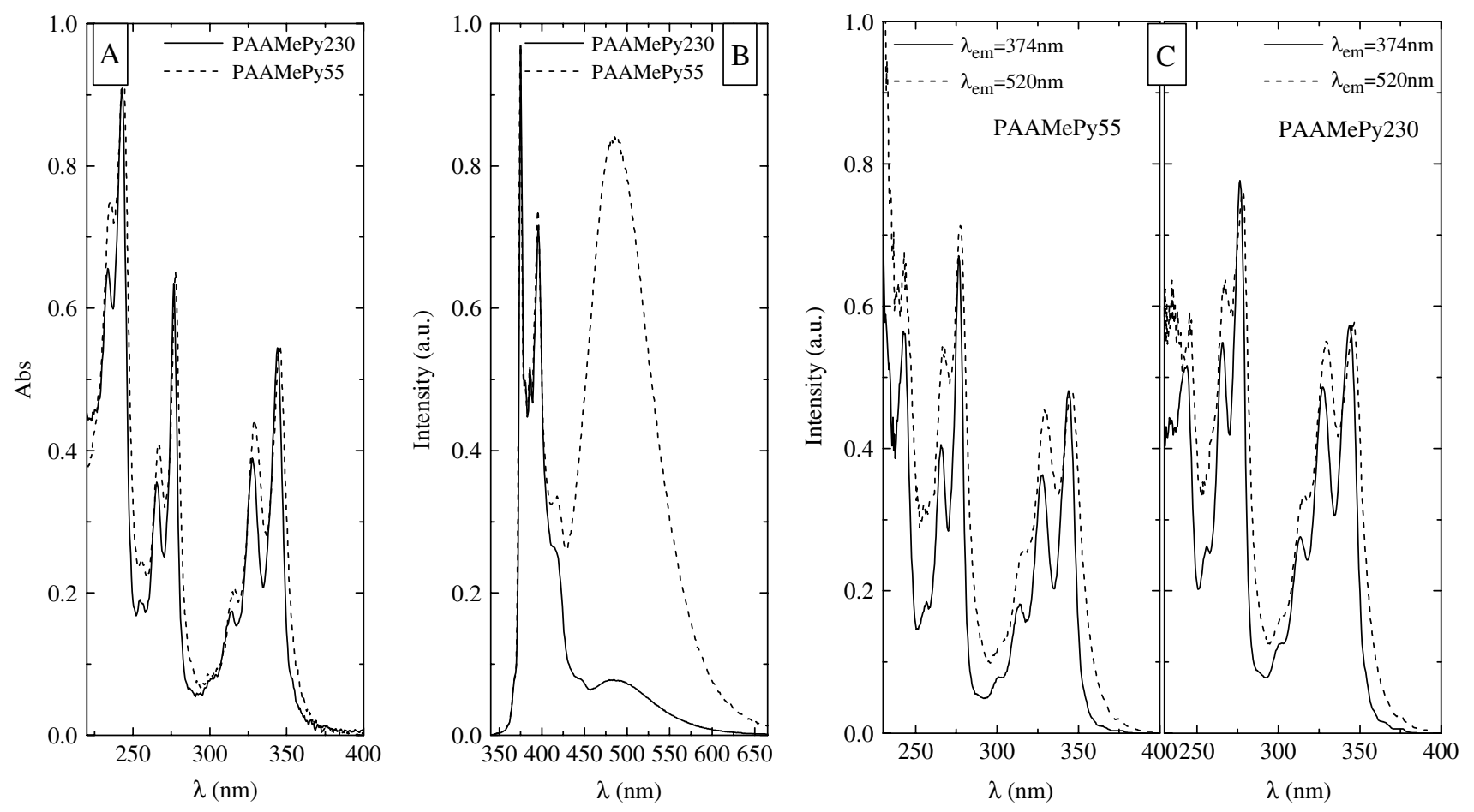

Figure 1. Absorption (A) and fluorescence emission (B) and excitation (C) spectra of PAAMePy with two degrees of labelling (PAAMePy230 and PAAMePy55) obtained at $\mathrm{pH}=3$ and $T=293 \mathrm{~K}$.

of the PAAMePy polymer will be, in the ground state, included into the $\mathrm{CD}$ cavity. In that case ground-state dimers will be formed, giving rise to a new absorption band which is clearly reflected in the increased broadening and changing in the absorption band of the PAAMePy polymers. Since the number of pyrene chromophores is in excess relative to the number of $\gamma$-CD molecules, a gradual increase of the $\gamma$-CD concentration will have an increasing effect on these changes. The limit of this increase seems, based on the absorption spectra, to be the solubility limit (of $\gamma-\mathrm{CD}$ ). However, as will be seen below, a limit of pyrenes involved in the inclusion complex formation is reached before the solubility limit. The addition of more $\gamma$-CD will therefore not change the absorption spectra of the PAAMePy polymers. The additional increase in optical density with added $\gamma$-CD results, most probably, from the circumstance that the dimers formed possess higher molar extinction coefficients relative to the monomer.

At this stage it is worth considering the possibility of higher order aggregates both in solution and in the presence of added $\gamma-C D$ (and $\beta-C D$ ). Higher order aggregates of pyrene (trimers, tetramers, etc) may be present particularly in a non-friendly environment such as water for the hydrophobic pyrene probe. When excited, these can form excimers within the preformed group. The ability to form an excimer (always involving only two units) depends on the cluster size as well as of the excess of vibrational energy. ${ }^{30} \mathrm{~A}$ dimer forms an excimer without excess energy, but the higher aggregates require an excess of vibrational energy above a certain minimum value. ${ }^{29}$
In water, the higher clusters of pyrene that may exist in the system studied here are not given any excess vibrational energy to enable them to rearrange and form an emissive sandwich-like (parallel or nonparallel) structure within the cluster. As a consequence they are non-emissive or 'dark' aggregates, i.e. not detected in our fluorescence measurements. When the interaction of the PAAMePy polymer with $\gamma$ $\mathrm{CD}$ (or $\beta$-CD) is promoted, the complex formed results from the inclusion of one or two (maximum) pyrene units into the $\mathrm{CD}$ cavity. It is therefore unlikely that higher order aggregates are present in this situation.

At $\mathrm{pH} 8$ there is basically no difference between the absorption spectra with and without $\gamma-C D$. Deprotonation could occur not only at the $\mathrm{COOH}$ groups of the PAA backbone chain, but also at the $\mathrm{OH}$ groups in the $\gamma$-CD. However, since the $\mathrm{p} K_{\mathrm{a}}$ of the $-\mathrm{OH}$ groups in $\beta$-CD is known to be $12.202^{8}$ it is not likely that deprotonation will occur for $\mathrm{pH}=8$. As suggested for pyrene in the $\gamma$-CD cavity, the two pyrene units are capable of arranging themselves in a parallel (or non-parallel) ${ }^{31,32}$ stacking pattern. ${ }^{10} \mathrm{We}$ therefore attribute this behaviour to be mainly due to the open conformation of the PAA chain, leading to less pyrene groups adjacent to each other. For both PAAMePy polymer systems at $\mathrm{pH} 8$, only those pyrene units that are very closely attached will form GSDs that can go into the $\mathrm{CD}$ cavity. This will effectively decrease the inclusion ability of $\gamma-\mathrm{CD}$ to pyrene units, leading to no changes on the absorption spectra of the PAAMePy polymers at $\mathrm{pH} 8$, yet changes are visible in the excitation and emission spectra showing some level of inclusion (see below). 

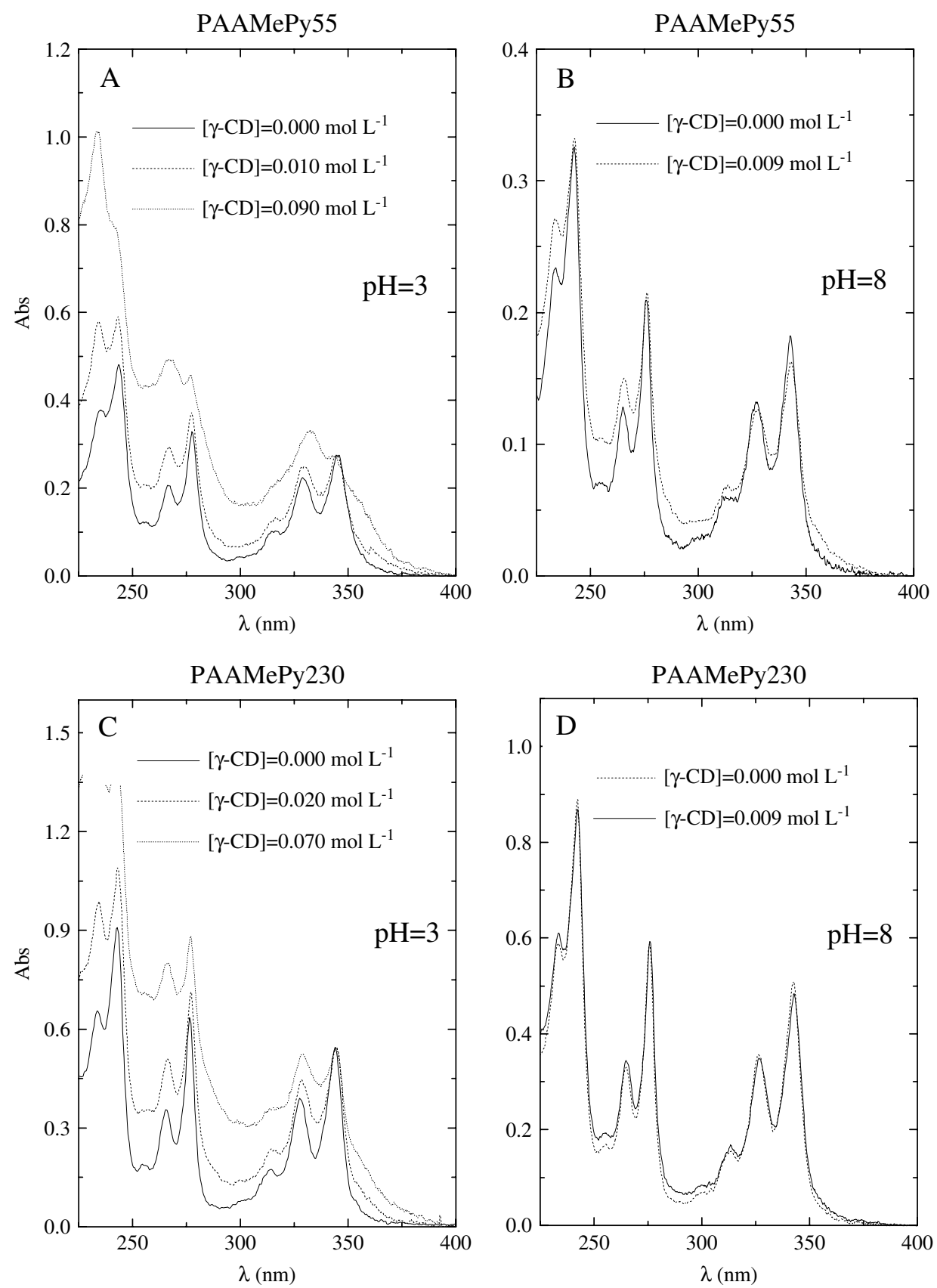

Figure 2. Absorption spectra for PAAMePy55 and PAAMePy230 obtained with various concentrations of $\gamma-\mathrm{CD}$ at $\mathrm{pH}=3$ and $8, T=293 \mathrm{~K}$.

\section{Fluorescence spectra}

The fluorescence emission spectra of PAAMePy polymers obtained with different concentrations of $\gamma-\mathrm{CD}$ at $\mathrm{pH}=3$ and 8 are shown in Fig. 3 .

In pure water, the intensity of the excimer emission band decreases with $\mathrm{pH} .{ }^{1}$ This decrease is followed by an increase in the monomer emission, and consequently the number of 'free' monomers increases. ${ }^{1}$ For acidic $\mathrm{pH}$, when $\gamma-\mathrm{CD}$ is added, a gradual increase in the excimer emission band is observed (Fig. 3). In this polymer system, the excimer emission band results from contributions of dynamic and ground-state dimers. ${ }^{1}$ Contrary to the situation observed in the absorption, at $\mathrm{pH}=8$ there is a variation of the emission spectra when $\gamma$-CD is added. This indicates that some degree of interaction between the PAAMePy polymers and $\gamma$-CD exists even in alkaline media (where the repulsive electrostatic forces between negative charges are present).

The variation of the excimer-to-monomer intensity ratio $\left(I_{\mathrm{E}} / I_{\mathrm{M}}\right)$ with the concentration of $\gamma-\mathrm{CD}$ is plotted in Fig. 4, which shows, for $\mathrm{pH}$ 3, an increase up to $[\gamma-\mathrm{CD}]=0.05 \mathrm{~mol} \mathrm{~L}^{-1}$, where a plateau is reached. It should be noted that there is an apparent maximum; however, this is due to the scattering of the data, since it can be observed, for example, that with excitation at $315 \mathrm{~nm}$ the value for the $I_{\mathrm{E}} / I_{\mathrm{M}}$ ratio at $[\gamma-\mathrm{CD}] \sim 0.04 \mathrm{~mol} \mathrm{~L}^{-1}$ is identical to that for $[\gamma-\mathrm{CD}] \sim 0.09 \mathrm{~mol} \mathrm{~L}^{-1}$. Moreover, the $I_{\mathrm{E}} / I_{\mathrm{M}}$ ratio is larger at acidic $\mathrm{pH}$ values than it is at alkaline values for the reasons mentioned above. Nevertheless, there is inclusion of some pyrene units into the 

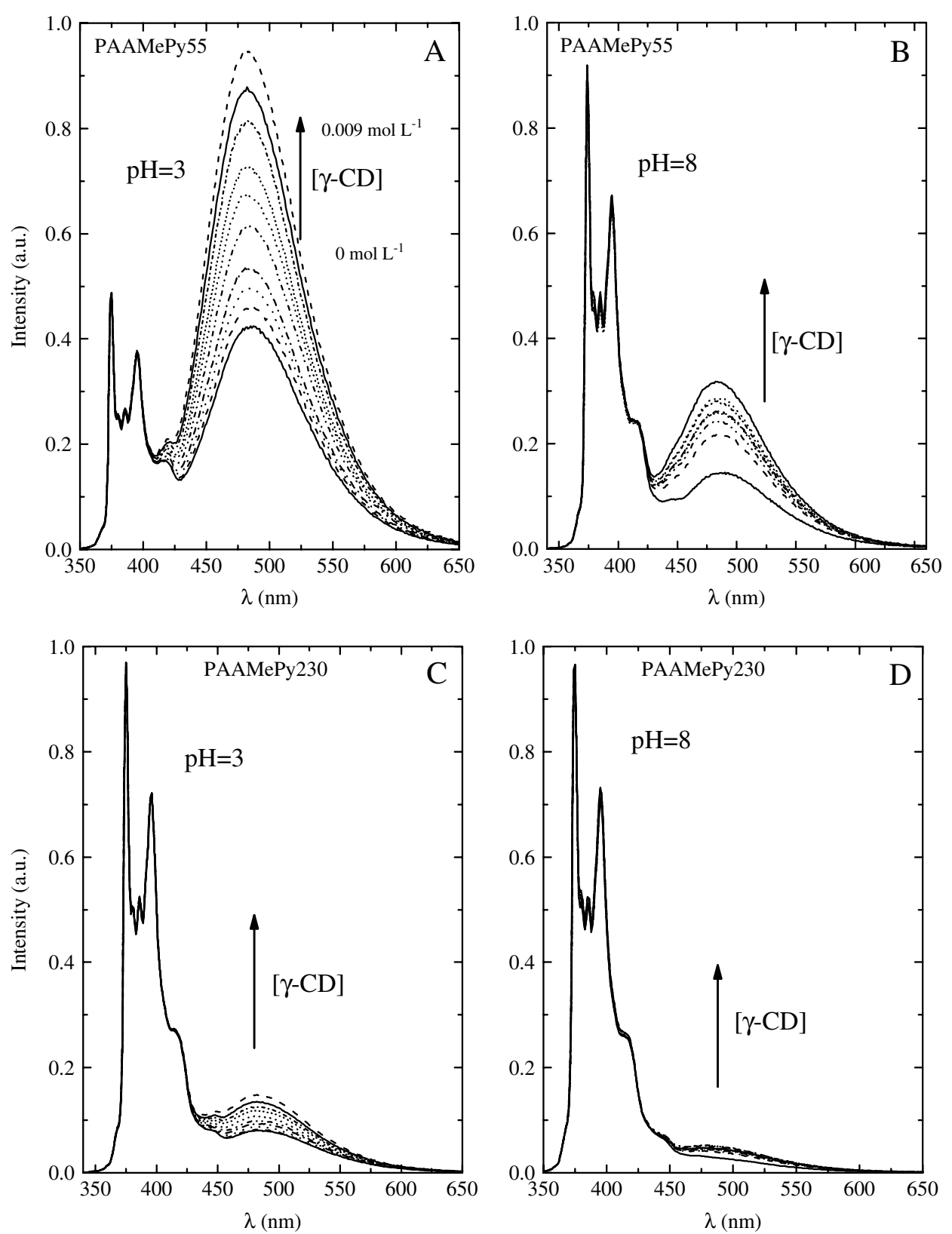

Figure 3. Fluorescence emission (normalized at $374 \mathrm{~nm}$ ) for PAAMePy55 and PAAMePy230 obtained with $\lambda_{\text {exc }}=335 \mathrm{~nm}$, at pH $=3$ and 8 for various concentrations of $\gamma-\mathrm{CD}([\gamma-\mathrm{CD}])$. In all four cases $[\gamma-\mathrm{CD}]$ varies from 0.000 to $0.009 \mathrm{~mol} \mathrm{~L}^{-1}$. For higher $\gamma-\mathrm{CD}$ concentrations see plots in Fig. 4.

$\gamma$-CD cavity at alkaline $\mathrm{pH}$ values, attested by the absolute value of 0.2 units resulting from the difference between pure water and $[\gamma-\mathrm{CD}]=0.003 \mathrm{~mol} \mathrm{~L}^{-1}$ at the excitation wavelength $315 \mathrm{~nm}$. This difference reaches a maximum $(0.25)$ when excitation at $350 \mathrm{~nm}$ is used (Fig. 4).

An identical behaviour is found for the lesslabelled PAAMePy230 polymer (Fig. 5). In fact, at $\mathrm{pH}=3$ the maximum difference between the minimum (absence of $\gamma-\mathrm{CD},[\gamma-\mathrm{CD}]=0 \mathrm{~mol} \mathrm{~L}^{-1}$ ) and maximum $\left([\gamma-\mathrm{CD}]=0.07 \mathrm{~mol} \mathrm{~L}^{-1}\right)$ values of the $I_{\mathrm{E}} / I_{\mathrm{M}}$ ratio is $\sim 0.9$ (with $\lambda_{\text {exc }}=335 \mathrm{~nm}$ ) whereas at $\mathrm{pH}=8$ this difference is only $\sim 0.03$ (with $\lambda_{\text {exc }}=$ $350 \mathrm{~nm}$ ).

In Figs 4 and 5 an additional observation is worth mentioning. The different excitation wavelengths used, although giving rise to very similar curves, show different $I_{\mathrm{E}} / I_{\mathrm{M}}$ absolute values. This is an obvious consequence of the fact mentioned above that GSD absorption predominantly occurs at longer wavelengths. As a result, the $I_{\mathrm{E}} / I_{\mathrm{M}}$ contribution resulting from excitation at longer wavelengths is higher, in absolute terms, than it is at shorter wavelengths.

However, it is also worth noting that, contrary to the situation found for the polymer in water, with the addition of $\gamma-\mathrm{CD}$, it is likely that intermolecular interactions are promoted. In fact, in the presence of $\gamma$-CD, the increase of the PAAMePy55 polymer concentration led to an increase of the $I_{\mathrm{E}} / I_{\mathrm{M}}$ ratio (see Fig. A2 in Appendix A) thus showing that more excimer (essentially GSD) is being formed 

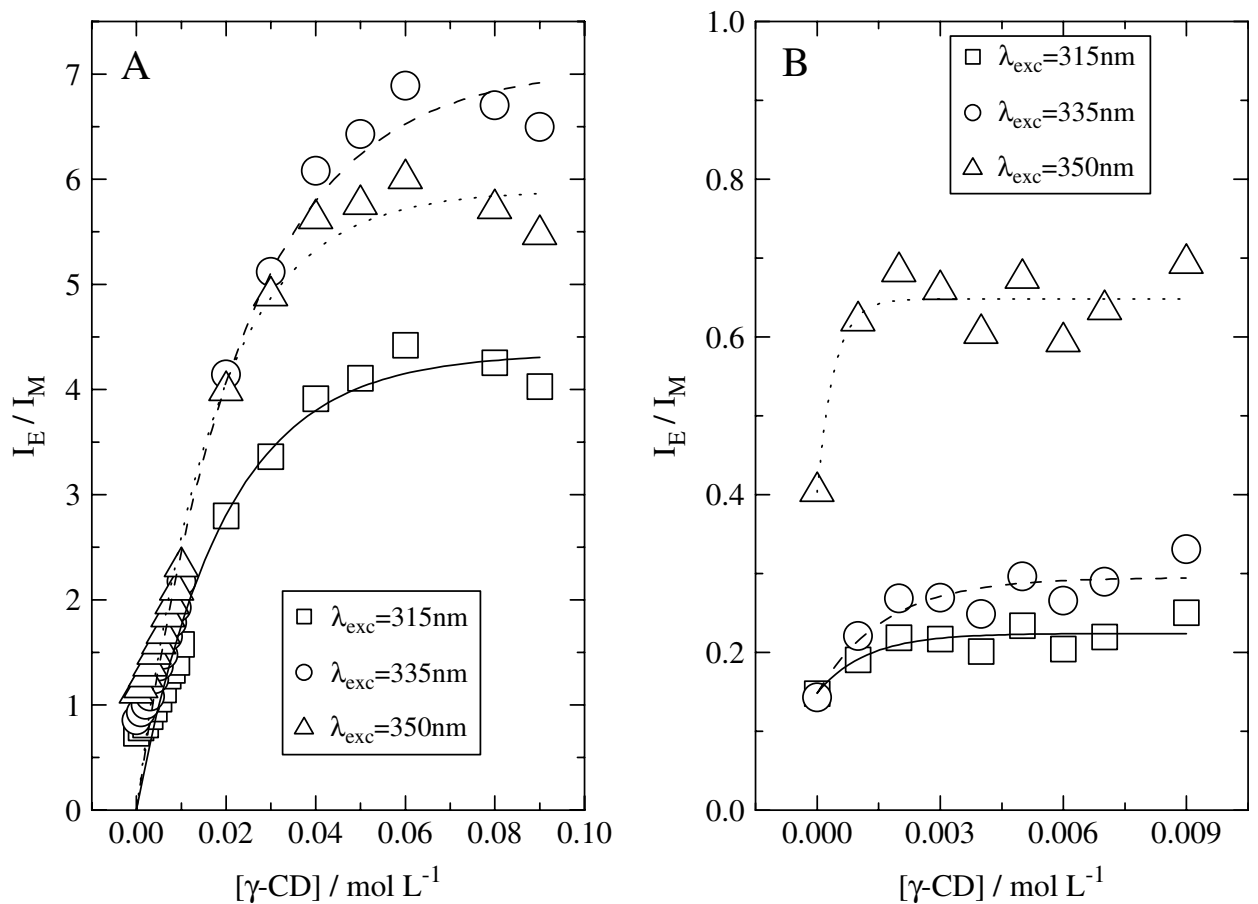

Figure 4. $I_{E} / I_{M}$ ratio (obtained with three different excitation wavelengths) as a function of $\gamma-C D$ concentration at (A) $p H=3$ and (B) $p H=8$ for PAAMePy55 at $T=293 \mathrm{~K}$. The lines are guides for the eye only.

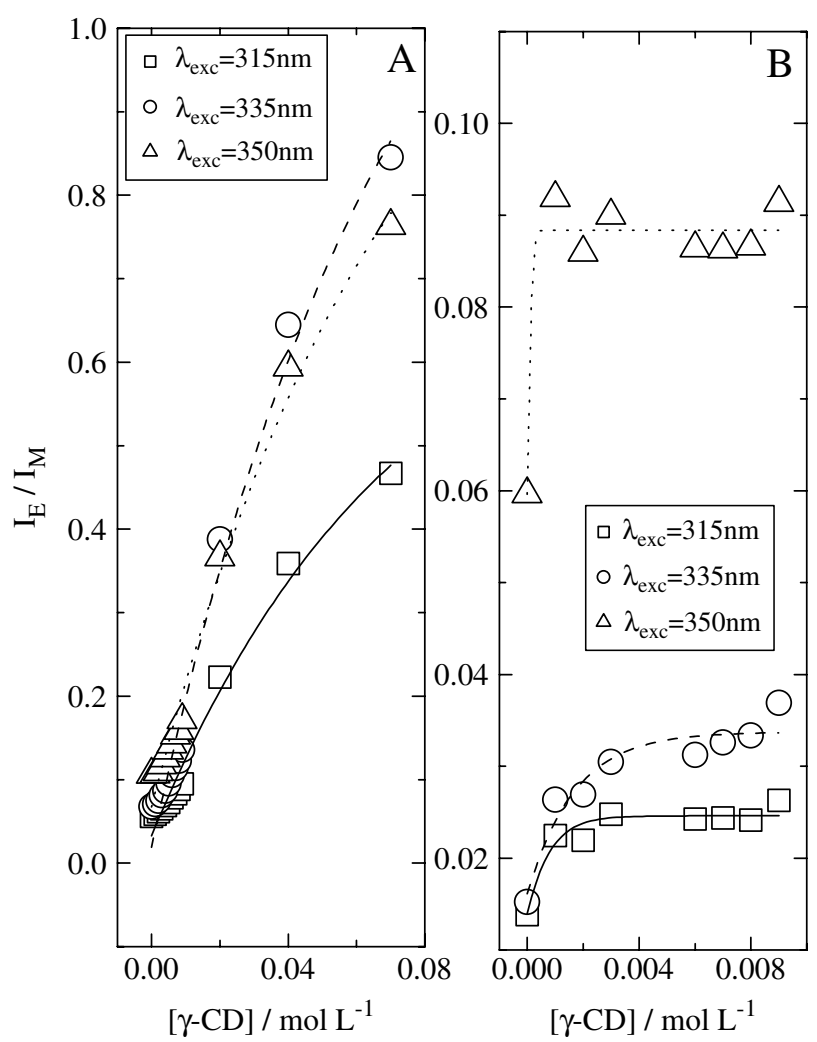

Figure 5. $I_{E} / I_{M}$ ratio (obtained with three different excitation wavelengths) as a function of $\gamma-\mathrm{CD}$ concentration at (A) $\mathrm{pH}=3$ and (B) $\mathrm{pH}=8$ for PAAMePy230 at $T=293 \mathrm{~K}$. The lines are guides for the eye only.

due to this new level of polymer interaction. The presence of $\gamma-\mathrm{CD}$, favouring the inclusion of two pyrene units per unit of $\gamma-\mathrm{CD}$, which can now be from a single chain (intramolecular) or from two different chains (intermolecular), leads inevitably to a more cooperative degree of interaction between PAA chains.

As expected, in the case of the interaction of $\beta$-CD with PAAMePy polymers, basically no dependence (or very small) on the concentration of the $\mathrm{CD}$ is observed. Figure 6 shows that the main difference in the behaviour shown results from the $I_{\mathrm{E}} / I_{\mathrm{M}}$ values obtained in water and the value corresponding to the first addition of $\beta$-CD, since no change is obtained from there on. This clearly establishes that in the present case, as expected, the $\beta$-CD only supports the inclusion of a single pyrene unit and therefore the result is that the increase in the $I_{\mathrm{E}} / I_{\mathrm{M}}$ ratio of the PAAMePy polymers with $\beta$-CD concentration is very small. However, the small change (from water to added $\beta$-CD) reflects the incorporation of pyrene monomers and the subsequent inhibition (by encapsulation of a single pyrene unit) of more excimer (static or dynamic) formation.

\section{Fluorescence excitation spectra}

The fluorescence excitation spectra for PAAMePy55 at $\mathrm{pH}=3$ collected at the monomer and excimer regions with different concentrations of $\gamma-\mathrm{CD}$ are presented in Fig. 7. It is clearly observed that the introduction of $\gamma$-CD induces changes in the different (collection at different emission wavelengths) excitation spectra of PAAMePy polymers. In fact, in water at $\mathrm{pH}=3$ and with the absence of $\gamma$ $\mathrm{CD}$, the difference between the spectra collected for the monomer $(374 \mathrm{~nm})$ and excimer $(520 \mathrm{~nm})$ results from the existence of GSDs. ${ }^{1}$ Nevertheless, 

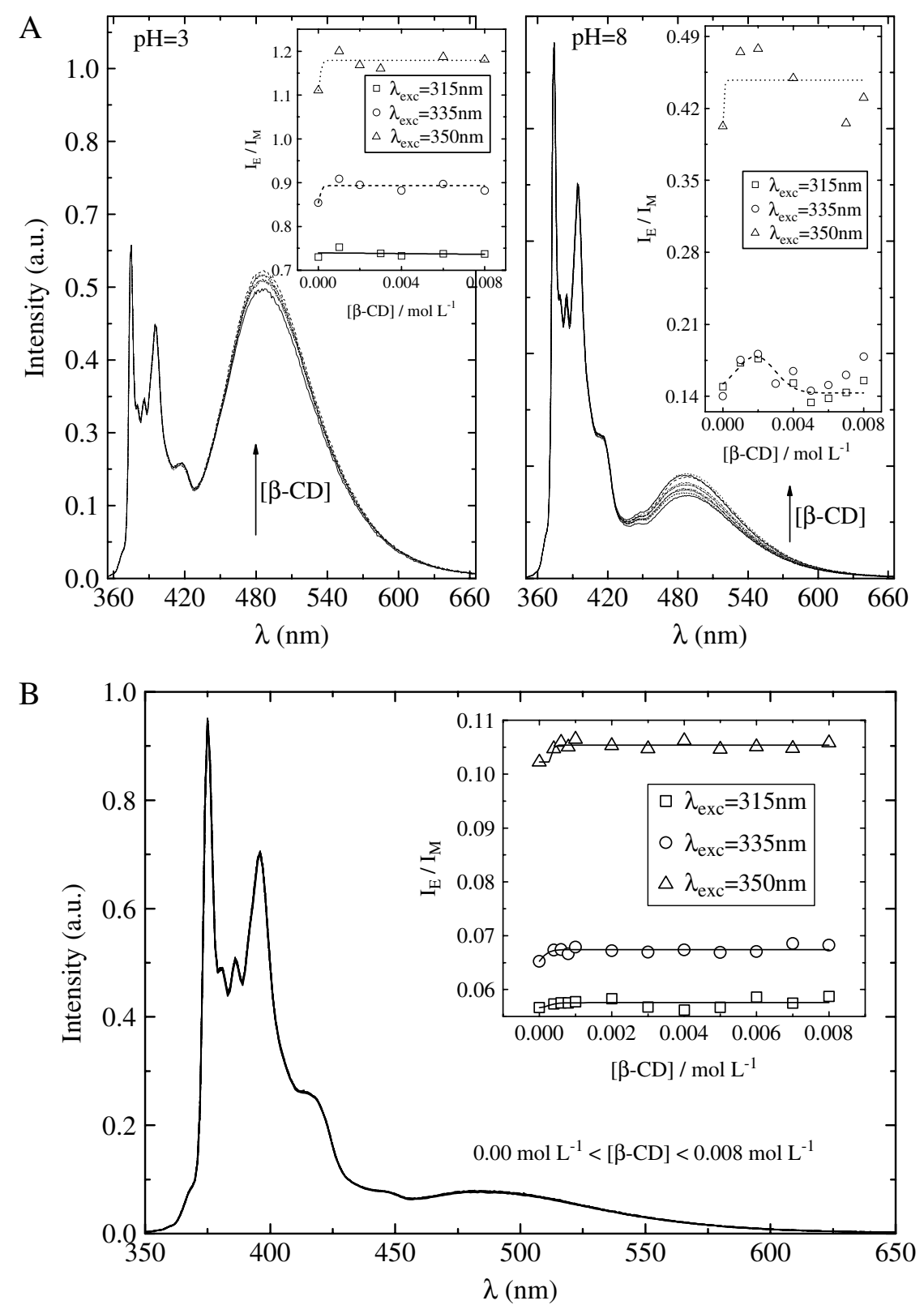

Figure 6. Normalized fluorescence emission spectra for (A) PAAMePy55 obtained at $\mathrm{pH}=3$ and 8 with $\lambda_{\text {exc }}=335 \mathrm{~nm}$ as a function of $\beta$-CD concentration and (B) for PAAMePy230 obtained at $\mathrm{pH}=3$ with $\lambda_{\mathrm{exc}}=335 \mathrm{~nm}$ as a function of $\beta$-CD concentration; $T=293 \mathrm{~K}$. The insets show the dependence of the $I_{\mathrm{E}} / \mathrm{I}_{\mathrm{M}}$ ratio on the $\beta-\mathrm{CD}$ concentration, respectively, and the lines are guides to the eyes only. In all cases, $[\beta-\mathrm{CD}]$ varies from 0.000 to $0.008 \mathrm{~mol} \mathrm{~L}^{-1}$.

there is also some degree of dynamic contribution for excimer formation. ${ }^{1}$ The addition of a small quantity of $\gamma$-CD completely changes the shape of the obtained excitation spectra collected at the excimer region (Fig. 7). This is particularly evident in the intensities of the vibronic modes relative to the lower energy transition (band $\mathrm{I}$ in Fig. 7(A)), where the addition of $\gamma$-CD results in a change in the relative intensities of the modes. With increasing $\gamma$-CD concentration, the change in shape of the band becomes more distorted and an additional change is also visible for the transition/band identified as II in Fig. 7(A). Albeit that the observed modification in the shape of the band(s) seems to change gradually with the addition of $\gamma$-CD, no further modifications seem to occur after $[\gamma-\mathrm{CD}] \approx 0.02 \mathrm{~mol} \mathrm{~L}^{-1}$.
It is noted that an identical behaviour is found for the lower substituted polymer, PAAMePy230 (Fig. 7(B)). This means that association of two pyrene units inside the $\gamma$-CD cavity is controlling the associative behaviour of these systems. This is a well-known phenomena occurring with pyrene. ${ }^{10}$ Yet to our knowledge there has never been a report of such intense change in the excitation spectra of pyrene (or pyrene-like molecules) by the introduction into a CD cavity. The remarkably different shape of the band (band I in Fig. 7), with inversion of the vibronic modes (intensity progression) of this band, is presumably a consequence of the coexistence of a parallel sandwich with non-parallel sandwich-like excimers. ${ }^{33,34}$

Unexpectedly, at alkaline $\mathrm{pH}$, there are also changes in the shape of the excitation spectra collected at 

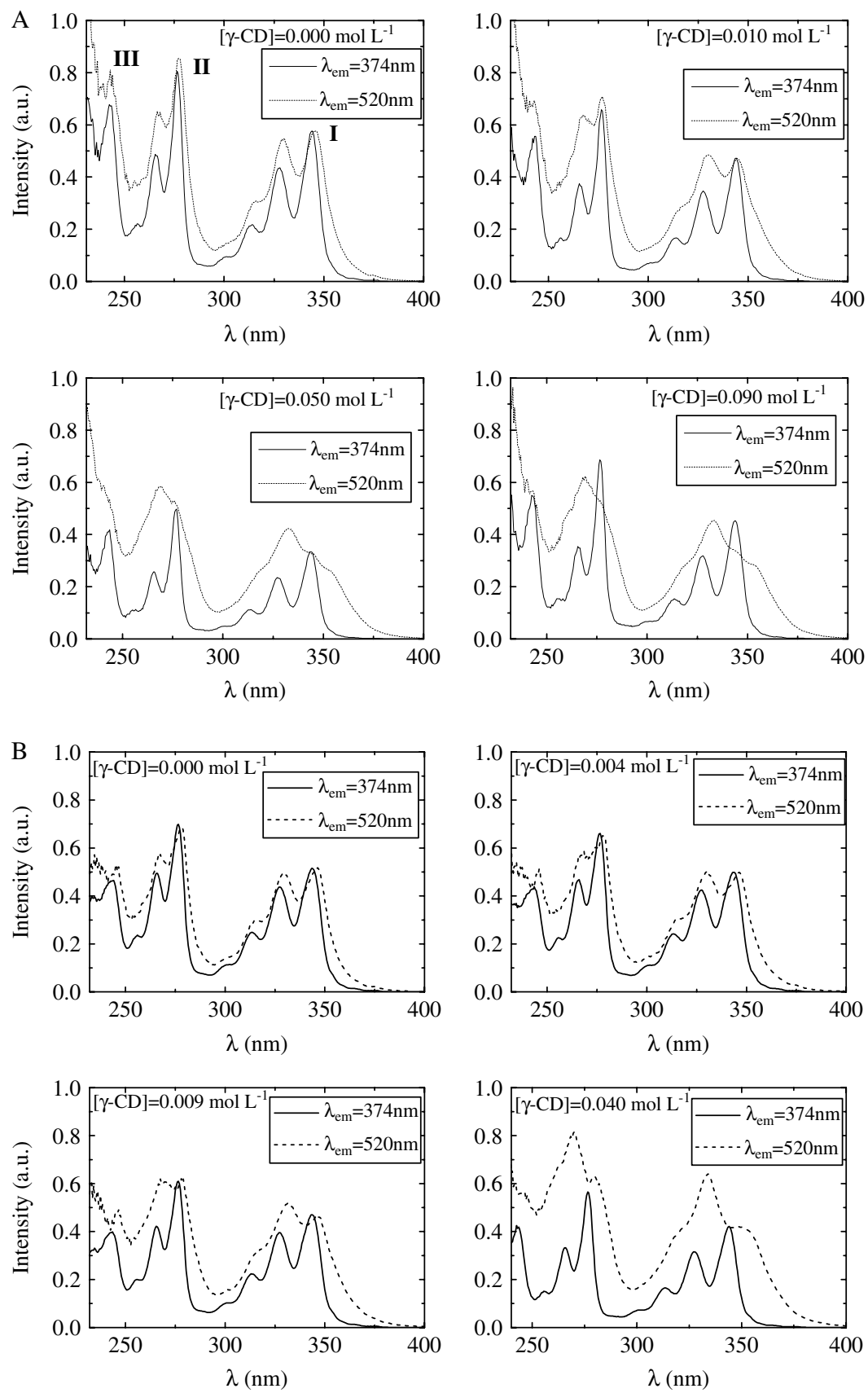

Figure 7. Fluorescence excitation spectra for (A) PAAMePy55 and (B) PAAMePy230 obtained at two different emission wavelengths, $374 \mathrm{~nm}$ (full line) and $520 \mathrm{~nm}$ (dashed line) for different concentrations of $\gamma-\mathrm{CD}$ at $\mathrm{pH} \approx 3$ and $T=293 \mathrm{~K}$.

the two wavelengths (Fig. 8). In fact, in pure water at $\mathrm{pH}=8$, differences in the excitation spectra are already present as a consequence of the proximity of some pyrene groups whose hydrophobicity leads to ground-state association. The addition of $\gamma-\mathrm{CD}$ promotes an even more significant change in the excitation spectra. This is a consequence of the hydrophobic nature of the CD cavity that supports the inclusion of two pyrene units and is, consequently, their preferred location in order to avoid water contact. Remember that at alkaline $\mathrm{pH}$ values, there is a substantial electrostatic repulsion between the deprotonated PAA carboxylic groups responsible for the lower values of the absolute $I_{\mathrm{E}} / I_{\mathrm{M}}$ ratio values when compared with the situation in acidified media. ${ }^{1}$
Nevertheless, a number of local neighbouring pyrene units will be close enough to be incorporated in the same $\gamma$-CD, leading to GSD formation and consequently to the observed differences in the excitation spectra in Fig. 8.

To further explore this point, regarding the influence of the proximity of pyrene groups, we obtained the excitation spectra for PAAMePy230 (Fig. 8(B)) under the same conditions as for PAAMePy55 (Fig. 8(A)). It is clear that the lower degree of labelling does not exclude GSD formation since the presence of some pyrene units leads immediately to association.

Moreover, it is possible to extract some further information based on some additional spectral parameters (from absorption and fluorescence excitation spectra). 

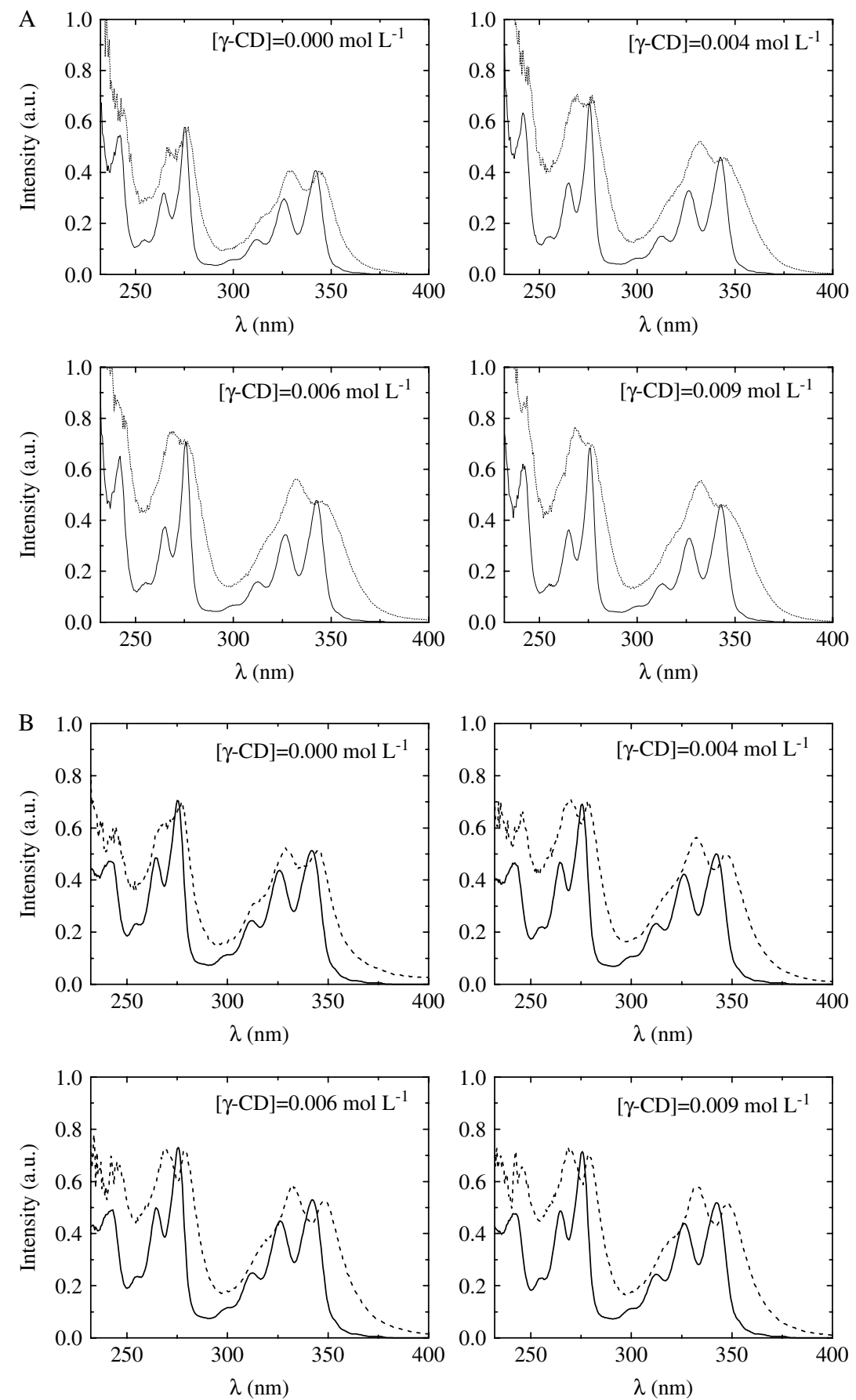

Figure 8. Fluorescence excitation spectra for (A) PAAMePy55 and (B) PAAMePy230 obtained at two different emission wavelengths, $374 \mathrm{~nm}$ (full line) and $520 \mathrm{~nm}$ (dashed line) for different concentrations of $\gamma-\mathrm{CD}$ at $\mathrm{pH} \approx 8$ and $T=293 \mathrm{~K}$.

From the absorption spectra, these are the difference between the wavelength maximum of the two polymers $\left(\Delta \lambda_{1}\right)$ and the peak-to-valley ratio, $P_{\mathrm{A}}$ (see Table 1 ). From the excitation spectra, the parameters are the shift in the wavelength maximum of the spectra collected in the two regions $\left(\Delta \lambda_{2}\right)$ and the differences in the peak-to-valley ratio relative to the $(0,1)$ transition observed in the monomer $\left(P_{M}\right)$ and excimer $\left(P_{\mathrm{E}}\right)$ excitation spectra, respectively. ${ }^{1,35-37}$ In an ideal situation of non-GSD formation the values for these parameters should be identical to zero. The departure from zero, obtained for these parameters, are based on the idea that a more or less intense absorption band due to ground-state aggregates is buried underneath the intense monomer band. ${ }^{1}$ With the gradual increase of the aggregates or environment where those are formed, all the mentioned features tend to change and the obtained values can be used as a complementary tool for discussion on the nature and type of aggregation. The data in Table 1 summarize the obtained parameters for the two studied PAAMePy polymers at two different $\mathrm{pH}$ values and with a wide range of $\gamma$-CD concentrations.

For PAAMePy55 at $\mathrm{pH} \approx 3$ there is an increase of the $\Delta \lambda_{2}$ values with increasing $\gamma$-CD concentration. This shows that there is an increase in the contribution 
Table 1. Photophysical data at $293 \mathrm{~K}$, taken from the absorption and fluorescence excitation spectra for PAAMePy230 and PAAMePy55 (in parentheses) considering the second vibronic more intense peak in the excimer excitation spectra in water (at different $\gamma$-CD concentrations) at two different $\mathrm{pH}$ values ( $\mathrm{pH}=3$ and 8 ). See text for meaning of symbols

\begin{tabular}{|c|c|c|c|c|c|c|}
\hline$[\gamma-\mathrm{CD}]\left(\mathrm{mol} \mathrm{L}^{-1}\right)$ & $\Delta \lambda_{1}$ & $\Delta \lambda_{2}$ & $P_{\mathrm{A}}$ & $P_{\mathrm{M}}$ & $P_{\mathrm{E}}$ & $P_{\mathrm{M}}-P_{\mathrm{E}}$ \\
\hline \multicolumn{7}{|l|}{$\mathrm{pH}=3$} \\
\hline 0.001 & 1.0 & 2.5 & $2.54(1.92)$ & 1.88 & 1.38 & 0.50 \\
\hline 0.002 & 2.3 & 3.0 & $2.48(1.86)$ & 1.85 & 1.32 & 0.53 \\
\hline 0.003 & 1.0 & 2.5 & $2.43(1.86)$ & 1.87 & 1.29 & 0.58 \\
\hline 0.004 & 1.7 & 3.0 & 2.37 (1.82) & 1.86 & 1.23 & 0.63 \\
\hline 0.006 & 0.8 & 3.0 & $2.25(1.72)$ & 1.88 & 1.18 & 0.70 \\
\hline 0.008 & 1.0 & 3.5 & 2.19 (1.62) & 1.92 & 1.12 & 0.80 \\
\hline 0.020 & 0.8 & $3.5(5.5)$ & $1.74(1.26)$ & 2.25 (1.94) & $1.04(1.20)$ & $1.21(0.74)$ \\
\hline 0.030 & & $(5.5)$ & $(1.15)$ & (1.91) & (1.23) & (0.68) \\
\hline 0.040 & 3.2 & $4.5(5.0)$ & $1.47(1.06)$ & 2.44 (1.92) & $1.02(1.26)$ & $1.42(0.66)$ \\
\hline 0.050 & & $(5.0)$ & (1.09) & (1.93) & (1.29) & $(0.64)$ \\
\hline 0.060 & & $(4.5)$ & $(1.06)$ & (1.92) & $(1.30)$ & $(0.62)$ \\
\hline 0.090 & & $(4.5)$ & (1.04) & (1.91) & $(1.35)$ & $(0.56)$ \\
\hline \multicolumn{7}{|l|}{$\mathrm{pH}=8$} \\
\hline 0.000 & 0.2 & $4.0(4.0)$ & $2.34(2.27)$ & 1.84 (1.89) & $1.16(1.24)$ & $0.68(0.65)$ \\
\hline 0.004 & 0.2 & $5.0(5.5)$ & $2.51(2.05)$ & 1.89 (1.91) & $1.15(1.20)$ & $0.79(0.71)$ \\
\hline 0.006 & 0.8 & $6.0(6.0)$ & $2.40(1.91)$ & 1.83 (1.89) & $1.21(1.22)$ & $0.62(0.67)$ \\
\hline 0.009 & 0.4 & $5.0(6.5)$ & 2.37 (1.78) & 1.85 (1.94) & $1.21(1.23)$ & $0.64(0.71)$ \\
\hline
\end{tabular}

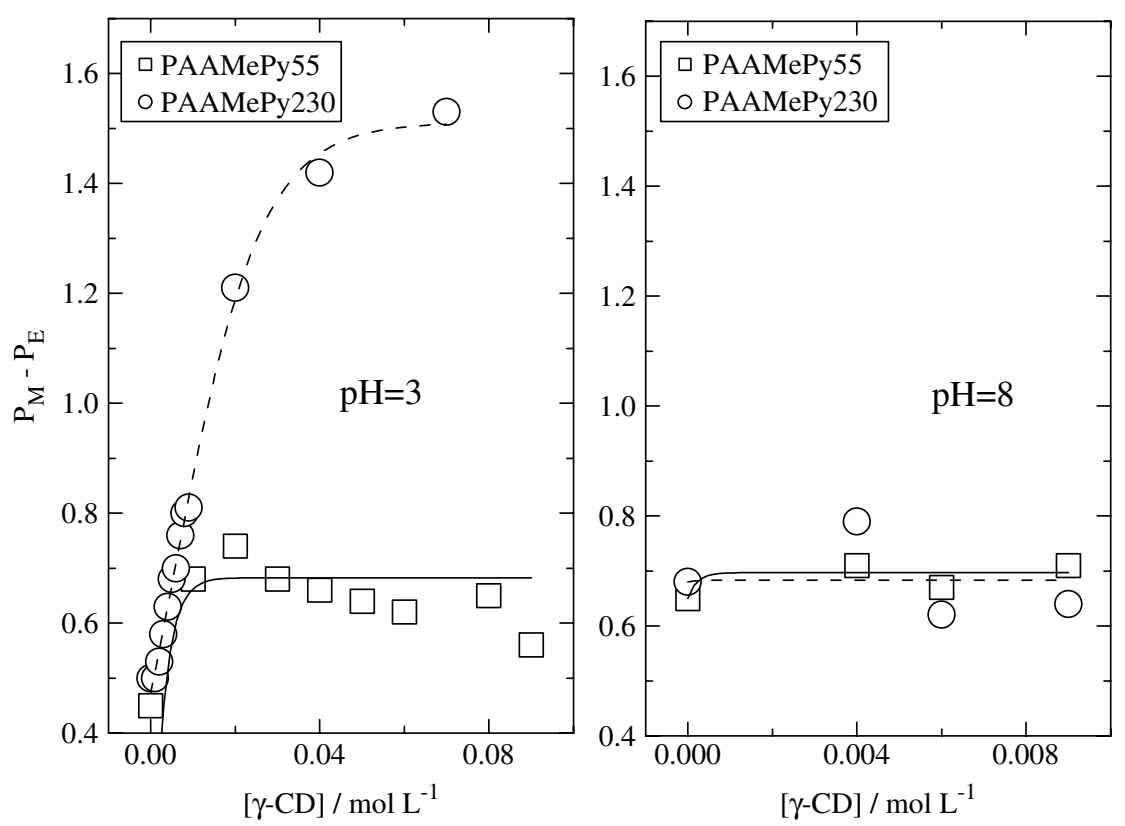

Figure 9. $P_{\mathrm{M}}-P_{\mathrm{E}}$ difference as a function of $\gamma-\mathrm{CD}$ concentration for PAAMePy55 and PAAMePy230, at $\mathrm{pH} \approx 3$ and 8 and $T=298 \mathrm{~K}$. The lines are guides for the eye only.

of GSDs to the overall excimer formation. Also the decrease in $P_{\mathrm{A}}$ with increasing $\gamma$-CD concentration reflects the increase in preformed dimer contribution.

At alkaline $\mathrm{pH}$ values the $\Delta \lambda_{1}$ and $\Delta \lambda_{2}$ values increase with increasing $\gamma$-CD concentration, for both polymers. At $\mathrm{pH}=8$, the total (but not necessarily the relative ${ }^{1}$ ) contribution of GSD is smaller than at $\mathrm{pH} \approx 3$, for the same $\gamma$-CD concentration. Still, the increase in the $\gamma$-CD concentration promotes an increase in the GSD contribution also at higher $\mathrm{pH}$.

Instead of analysing the individual trend of the $P_{\mathrm{E}}$ and $P_{M}$ parameters with the $\gamma$-CD concentration, what is relevant is to observe the behaviour resulting from the difference between these two parameters (see Fig. 9). The analysis of this difference shows that albeit PAAMePy230 is less pyrene-labelled than PAAMePy55, in the first case the $P_{M}-P_{\mathrm{E}}$ difference is much more pronounced and significant than it is for the higher labelled polymer at $\mathrm{pH}=3$. This shows that there is a significant and relevant contribution of GSDs in PAAMePy230 with the increase in $\gamma$-CD concentration at acidic $\mathrm{pH}$ (Fig. 9). At $\mathrm{pH} 8$, the polymers present similar values.

Additional aspects of the rich pyrene photophysics are, for example, the ratio between the first and third vibronic bands of monomer emission of pyrene $\left(I_{1} / I_{3}\right.$ ratio) known to exhibit sensitivity to changes in the polarity of the local environment felt by 
the chromophore. This $I_{1} / I_{3}$ ratio increases with polarity (or dielectric constant) of the solvent ${ }^{38,39}$ and has been extensively used as a polarity scale. ${ }^{38-46}$ It has therefore been possible to predict the critical micelle concentration (CMC) and the critical aggregation concentration (CAC) from $I_{1} / I_{3}$ or from the $I_{\mathrm{E}} / I_{\mathrm{M}}$ ratio dependences with, for example, the concentration of surfactant, polymer, etc. We can therefore extract additional experimental information from the dependence of the $I_{1} / I_{3}$ ratio for the PAAMePy polymers on the concentration of $\gamma-\mathrm{CD}$ (Fig. 10).

In fact, it is well known that the ratio of the fluorescence intensity of the pyrene vibronic bands $I_{1}\left[S_{0}(v=0) \leftarrow S_{1}(v=0)\right]$ and $I_{3}\left[S_{0}(v=1) \leftarrow\right.$ $\mathrm{S}_{1}(v=0)$ ], i.e. $I_{1} / I_{3}$, reflects the polarity of the local medium surrounding the chromophore. ${ }^{38,39}$ As was found earlier, the $I_{1} / I_{3}$ ratio increases with polarity (or dielectric constant) of the solvent. ${ }^{38,39}$ In the present study, as an example, for PAAMePy55 the $I_{1} / I_{3}$ ratio decreases from a maximum of $\sim 1.95$ (the difference also depends on the excitation wavelength) to a minimum of $\sim 1.6$ (see Fig. 10) at higher $\gamma$ $\mathrm{CD}$ values, which indicates a clear change in the microenvironment felt by pyrene. According to Dong and Winnik ${ }^{38}$ the $I_{1} / I_{3}$ ratio for free pyrene in water is equal to 1.87 . This shows that the medium felt by the pyrene chromophores is gradually changing to a more hydrophobic environment by encapsulation of the pyrene units. Note that in the case of PAAMePy230, albeit there is a decrease with added $\gamma-\mathrm{CD}$ due to the low pyrene content, the system is not sensitive enough. Also note that at alkaline $\mathrm{pH}$ values and for the two PAAMePy polymer systems, the $I_{1} / I_{3}$ ratio seems to increase - which means that little interaction exists with the $\mathrm{CD}$ - since the polymer 'sees more water' and is therefore in a more extended conformation at higher $\mathrm{pH}$ values.

\section{Time-resolved fluorescence data for PAAMePy polymers in aqueous solutions with $\beta$ - and $\gamma$-CD} In a previous work $^{1}$ we showed that PAAMePy in aqueous solution experiences the contribution of both static and dynamic excimers. Preformed dimers (GSDs) coexisting with dynamic excimers is a phenomenon commonly observed in kinetic studies with pyrene derivatives. ${ }^{35}$ In terms of steady-state emission spectra, it is difficult to differentiate them (one from the other) since both normally emit in the same wavelength region, i.e. the long-wavelength emission band results from the contribution of both static and dynamic excimers. However, it is possible to prove the existence of pre-associated dimers by examining the $I_{\mathrm{E}} / I_{\mathrm{M}}$ ratio measured at different excitation wavelengths and by time-resolved spectroscopy. ${ }^{1}$

The fluorescence decay of PAAMePy polymers showed to be multiexponential. ${ }^{1}$ The system presents different outputs depending on the solvent media. In good solvents (for the pyrene probe) such as dioxane or methanol, the fluorescence decays are, in the monomer emission region, properly fitted with triple
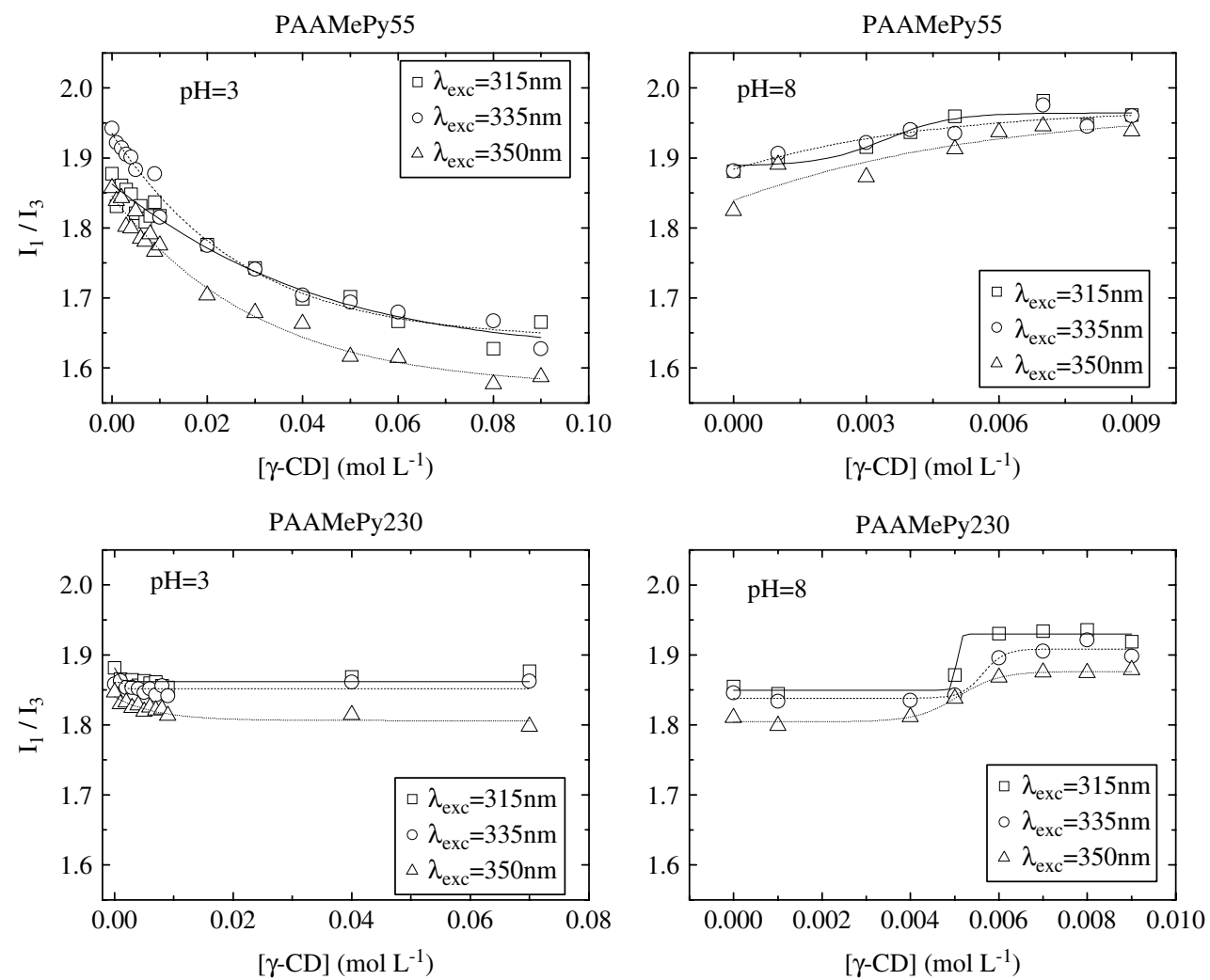

Figure 10. Variation of $I_{1} / l_{3}$ ratio for the PAAMePy55 and PAAMePy230 polymers at $\mathrm{pH} \approx 3$ and 8 , as a function of $\gamma$-CD concentration obtained with three excitation wavelengths at $T=293 \mathrm{~K}$. 
exponential laws, whereas in the excimer emission region in general two exponentials are enough to fit the decays. ${ }^{1,5,31,47}$ The analysis of the fluorescence decays reveals two identical short decay times $\left(\tau_{1}\right.$ and $\tau_{2}$ ), obtained at different emission wavelengths, plus an additional long decay time $\left(\tau_{3}\right)$ in the monomer emission region. ${ }^{1,5,31,47}$ The decay time $\tau_{2}$ corresponds to the emission of monomers that are able to give rise to excimers in the excited state (abbreviated as MAGRE) and $\tau_{1}$ is the excimer decay, which appears in the monomer emission wavelength as the component associated to the excimer-to-monomer reversibility process. $^{1}$ The additional long lifetime component present in the monomer decay has a decay time identified as $\tau_{3}$ and is connected to the emission of isolated monomers.

However, this description of the fluorescence decay does not seem to be the general rule for PAAMePy polymers in water and in aqueous systems as it involves the addition of CD. Instead, two excimers (with decay times $\tau_{1}$ and $\tau_{4}$ ) and two monomers (with decay times $\tau_{2}$ and $\tau_{3}$ ) are present. In fact, when the decays are collected at $375 \mathrm{~nm}$ (monomer region) and at $520 \mathrm{~nm}$ (excimer region) the decays are triple-exponential but only with two common decay times. This indicates more complex kinetics than in dioxane or methanol. In the excimer emission region, the additional decay term was tentatively assigned to a second excimer, on the basis of the discussion and observation that are described below.

The conventional wisdom (including several textbooks) ${ }^{48,49}$ looks at excimer formation involving aromatic molecules with an adopted conformation displaying a sandwich-type (parallel orientation of the two chromophoric units) geometry. However, others $^{32}$ found for intramolecular excimer formation with 1,3-(1,1'-dipyrenyl)propane [1Py(3) 1 Py] a tripleexponential decay. By comparison with the decay times of 1,3-(2,2'-dipyrenyl)propane [2Py(3)2Py] (which could be fitted with a double-exponential decay) they showed that the triple-exponential decays of $1 \mathrm{Py}(3) 1 \mathrm{Py}$ resulted from the presence of two excimers. The shortest lived excimer (the more stable excimer) displays a twisted sandwich geometry with its lifetime identical to the lifetime of the intermolecular excimer ( $c a 60 \mathrm{~ns}),{ }^{50}$ while the longer lived ( $c a$ $140-150 \mathrm{~ns}$ ), less stable excimer has the parallel sandwich conformation. ${ }^{32}$ In our case the two longer decay times at the excimer emission decay time are similar to the lifetime of these two types of excimers of $1 \mathrm{Py}(3) 1 \mathrm{Py}$. Moreover this additional exponential term at the excimer region is not observed in good solvents, where there are less conformational restrictions to the polymer chain.

The proposed mechanism accounting for the presence of two excimers is shown in Scheme 3, where $\mathrm{E}_{1}$ and $\mathrm{E}_{2}$ represent the asymmetric (more stable) and symmetric (less stable) sandwich-like excimers. According to this scheme, $\mathrm{M}_{\mathrm{A}}$ stands for the isolated monomers and $\mathrm{M}_{\mathrm{B}}$ the MAGRE. Also in Scheme 3, $\beta$ is the fraction of light absorbed by the isolated monomers, $\mathrm{M}_{\mathrm{A}} ; \alpha(1-\beta)$ is the fraction of light used to excite the MAGRE chromophores, $M_{B}$; and $(1-\alpha)(1-\beta)$ is the fraction of light absorbed by the GSD of type $\mathrm{E}_{1}$ and $(1-\alpha)(1-\beta)(1-\gamma)$ that of the type $\mathrm{E}_{2}$. The rate constants in Scheme 3 are defined as: $k_{\text {ai }}$, rate constant for excimer formation (where $i=1,2$ ); $k_{\mathrm{di}}$, rate constant for excimer dissociation; $k_{\mathrm{M}}=1 / \tau_{\mathrm{M}}$ and $k_{\mathrm{Ei}}=1 / \tau_{\mathrm{Ei}}$, reciprocals of the unquenched lifetimes of the monomer and excimer, i.e. the rate constants for monomer and excimer decay, both through radiative and nonradiative pathways. By collecting the decays at (only) two emission wavelengths, as in the present work, there are more unknowns than available data (for more details see Appendix A). This is an ongoing study, which is currently in progress using a procedure and methodology analogous to the one used by Seixas de Melo and Maçanita, ${ }^{51}$ which will be applied to other related polymers in a forthcoming work.

Decays of PAAMePy55 in $\beta$ - and $\gamma-C D$

The fluorescence decays of PAAMePy55 in the presence of different concentrations of $\beta$-CD were obtained with different excitation wavelengths and two different $\mathrm{pH}$ values (see Appendix A). There is basically no variation in the fluorescence decay times and the pre-exponential factors at $\mathrm{pH} \approx 3$ and 8 with the added $C D$, which again gives emphasis to the fact that $\beta$-CD does not influence the photophysical behaviour of this polymer. This can be attested to both by the $I_{\mathrm{E}} / I_{\mathrm{M}}$ ratio shown in Fig. 6 where it is observed that this ratio reaches quickly a plateau and by the fluorescence decays (see Fig. A3 in Appendix A) where it can be observed that the decay components are, for identical $\mathrm{pH}$ values, basically identical. This absence of significant interactions between $\beta$-CD
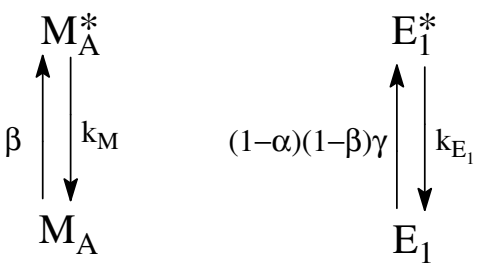
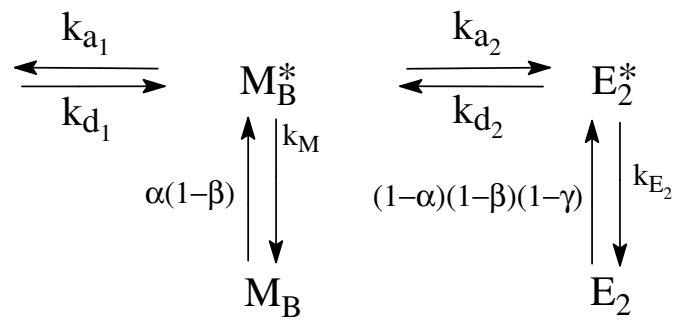

Scheme 3. Kinetic scheme for the PAAMePy polymers in water. 
and PAAMePy polymers suggests that the coil-like conformation acquired by the polymer (at acidic $\mathrm{pH}$ values) precludes little host-guest interaction with $\mathrm{CD}$. In this case the addition of $\beta$-CD only slightly influences the photophyical behaviour of the compounds by capping some (few) of the pyrene units. In the case of $\gamma-C D$ the driving force for more significant interactions is driven by the inclusion of two pyrene units.

Figure 11 shows that the sum of the pre-exponential factors at the excimer emission deviates from zero. This deviation is, as mentioned before, due to the existence of a fraction of pyrene groups that interact intramolecularly in the ground state (GSDs) that can directly absorb a fraction of the exciting light $[(1-\alpha)(1-\beta) \gamma$ and $(1-\alpha)(1-\beta)(1-\gamma)$ in Scheme 3]. If we compare the situation where excitation is made with two different wavelengths (315 and $350 \mathrm{~nm}$ ) (see Fig. A3 in Appendix A), it is observed that the negative amplitude value - preexponential factor $\left(a_{22}\right)$ - becomes progressively less negative with increasing excitation wavelength. This constitutes direct evidence for the existence of GSDs - predominantly absorbing in the red region $(350 \mathrm{~nm}) .{ }^{1}$ Moreover, the observation of the $a_{22}$ preexponential variation at $\mathrm{pH} \approx 3$ and 8 shows that it decreases in absolute value (see Appendix A). This means that, globally, excimer formation (in this case, dynamic contribution) loses importance as the $\mathrm{pH}$ increases, since the polymer chain adopts a more expanded conformation which leads to an increase in the distance between adjacent pyrene groups. As a consequence, the excimer contributions (both static and dynamic) will be smaller in the emission spectra. ${ }^{1}$
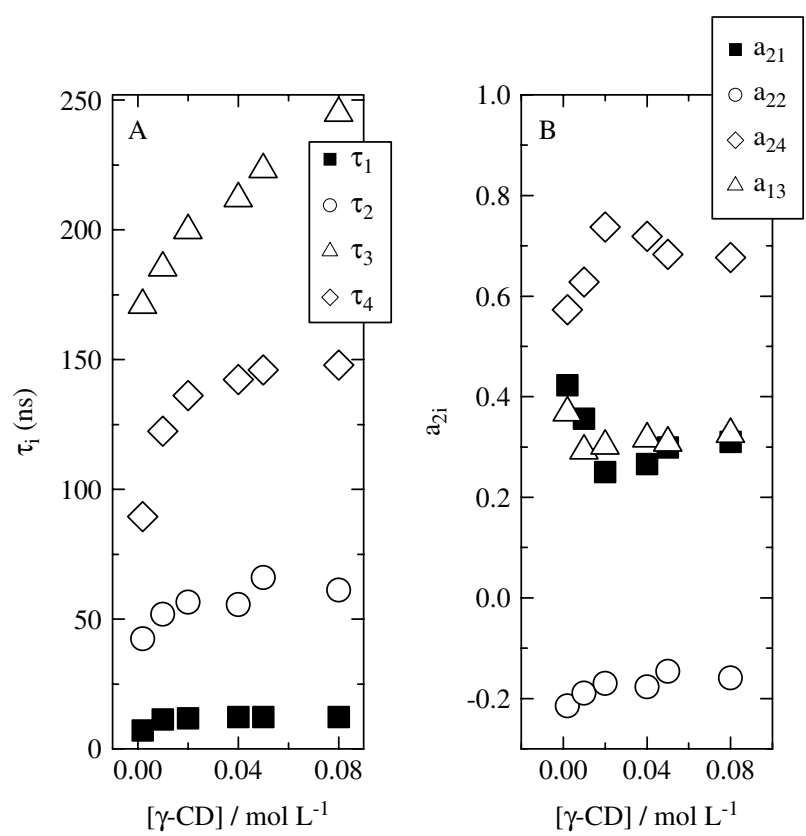

Figure 11. Fluorescence lifetimes $\left(\tau_{i}\right)$ and pre-exponential factors $\left(a_{i j}\right)$ obtained from the individual analysis of fluorescence decays, for PAAMePy55 at $\mathrm{pH} \approx 3$ as a function of $\gamma-\mathrm{CD}$ concentration with $\lambda_{\text {exc }}=315 \mathrm{~nm}$ and $T=293 \mathrm{~K}$.
At $\mathrm{pH}=3$, the fluorescence decays of PAAMepy55, obtained with different concentrations of $\gamma$-CD (see Figs 11 and A4), show that the longer lifetime $\left(\tau_{3}\right)$, attributed to isolated 'free' monomers, varies between 170 and $244 \mathrm{~ns}$. This strong variation in lifetimes may be due to a residual amount of oxygen present. Oxygen is a strong quencher of fluorescence probes with long lifetimes such as pyrene. The increase in the lifetime of the isolated chromophores is mainly due to the encapsulation of pyrene chromophores by $\gamma$ $\mathrm{CD}$, which basically reflects a decrease in the 'contact' with oxygen since it is present in a much smaller amount in the CD cavity. Even with good degassing procedures it is likely that the local environment felt by the pyrene chromophore in the PAA polymer can be responsible for some fluctuations in the decay time of the 'free' species. This is not, however, what happens in the present case. In fact, the gradual increase in $\gamma$-CD concentration provides a way via inclusion into the CD cavity for the pyrene chromophores to avoid exposure to oxygen, which gives rise to a higher value of the longer fluorescence lifetime. Nevertheless, albeit there is an increase of pyrene lifetime resulting from the addition of $\gamma$-CD and by nitrogen purging, oxygen still interacts with the included pyrene since purging may not remove all residual oxygen. ${ }^{11}$

Also interesting to discuss is the variation of the other decay times with the added amount of $\gamma$-CD. Remember that in water we are dealing with the presence of two excimers (with different conformation interactions) and two monomers (MAGRE and isolated). The variation of $\tau_{4}$ (associated with the parallel sandwich conformation and thus less stable excimer ${ }^{32,52,53}$ ) with $\gamma$-CD begins with an initial value of $\sim 90 \mathrm{~ns}$ and increases up to $\sim 148 \mathrm{~ns}$. This seems to indicate that the presence of $\gamma-\mathrm{CD}$ promotes a sandwich conformation (less stable excimer and therefore with a longer decay time). The decay time associated with the MAGRE monomers, $\tau_{1}$ in Fig. 11, increases slightly from $\sim 7$ to $\sim 12 \mathrm{~ns}$.

Figure 11(B) shows the pre-exponential factor dependence on the $\gamma$-CD concentration obtained at $370 \mathrm{~nm}\left(a_{1 i}\right)$ and at $520 \mathrm{~nm}\left(a_{2 j}\right)$, for PAAMePy55 polymer. The $a_{13}$ pre-exponential, associated with the fraction of excitable isolated chromophores $(\beta)$ decreases with the increase in the $\gamma$-CD concentration. This decrease is a direct consequence of the encapsulation of pyrene molecules by the $\gamma$-CD cavity. Consequently, the decrease in the level of 'free' pyrene monomers will be reflected in the $\beta$ value. The pre-exponentials $a_{22}, a_{21}$ and $a_{24}$ are associated with the decay time of the MAGRE monomer (and the formation time of the excimer negative pre-exponential) and with the excimer decay in an asymmetric and symmetric sandwich-like geometry, respectively. With the system under investigation, the sum of the pre-exponential factors at the excimer emission is always positive, which implies that a large fraction of excimers is already preformed. On 
increasing the $\gamma$-CD concentration, the $a_{22}$ preexponential becomes slightly less negative, which indicates that at high $\mathrm{CD}$ concentration the static route of excimer formation gains importance, i.e. more encapsulated pyrenes exist and thus also preexist in the ground state. The increase of the static route versus dynamic route is also related to the degree of labelling of the polymer. The greater the labelling of the polymer, the greater the dynamic excimer contribution. With higher labelled polymer, the number of pyrene guests will be in excess relative to the number of $\gamma$-CD host molecules. So, some of these pyrene groups would not form inclusion complexes with the CD and will therefore be 'free' to form excimers through a dynamic route. In a limit situation where all the pyrene groups are encapsulated in the $\mathrm{CD}$ cavities, no rise-time should be observed. The pre-exponentials $a_{21}$ and $a_{24}$ decrease and increase, respectively, with increasing $\gamma$-CD concentration, indicating that encapsulation of the pyrene groups favours the symmetric sandwich-like excimer geometry relative to the twisted sandwich-like geometry.

Finally, we briefly summarize the above-mentioned effects of $\gamma$-CD in the photophysical behaviour of PAAMePy polymers. As stated above, for acidic $\mathrm{pH}$ values, PAAMePy polymers adopt a more compact and coiled conformation where the pyrene groups are held together in a more hydrophobic environment. ${ }^{1}$ The result from the CD addition is the fact that fewer 'free' pyrene units will be available for GSD formation triggered by incorporation into the CD cavities. Also worth noting is the decrease in the MAGRE monomer contribution as a consequence of the incorporation, in the ground state, of the two units into the $\gamma$-CD cavity. Due to the solubility limit of $\gamma$-CD there are still plenty of pyrene units outside the cavity. However, we are presently testing a similar system with polymers with reduced degree of labelling and have observed a situation where all the pyrene chromophores are found inside the $\gamma$-CD, a situation evidenced by the absorption, excitation and (more important) fluorescence decays where the MAGRE monomer contribution has vanished.

For alkaline $\mathrm{pH}$ values the PAAMePy polymers are found in a more extended conformational stage due to the repulsive electrostatic forces between the $\mathrm{COO}^{-}$groups of the PAA backbone chain. Therefore, with the addition of $\gamma-\mathrm{CD}$ we observe only a slight increase in the $I_{\mathrm{E}} / I_{\mathrm{M}}$ ratio, which reflects the encapsulation of some pyrene units by some hydrophobic cavities of $\gamma$-CD (Figs 4 (B) and $5(\mathrm{~B})$ ).

\section{CONCLUSIONS}

1. The formation of inclusion complexes of $\beta$ and $\gamma$-CD with pyrene-labelled polyelectrolyte poly(acrylic acid) was followed using steady-state and fluorescence lifetime measurements.

2. Changes in the $\mathrm{pH}$ of the media influence the observed behaviour. In the case of $\gamma-\mathrm{CD}$ at acidic $\mathrm{pH}$ values the inclusion phenomena seem to prevail and to involve the inclusion of more than one pyrene unit, which enhances the groundstate excimer formation at the expense of the availability of 'free' monomers and to lower the formation of dynamic excimers. At alkaline $\mathrm{pH}$ values, the excimer formation is much reduced mainly because of repulsive interactions that exist between the ionized carboxylic groups of the PAA backbone chain, leading to a less proximity of available dimers for inclusion into the $\gamma$-CD molecules.

3. In the case of the interaction of PAAMePy polymers with $\beta$-CD, due to the availability of this CD cavity for a single pyrene unit, the photophysical behaviour of the polymers seems to be only slightly changed with the addition of $\beta$-CD.

\section{ACKNOWLEDGEMENTS}

Financial support from the Portuguese Science Foundation (POCI/QUI/55672/2004), FEDER, and the Swedish Research Council (KS) are acknowledged. TC acknowledges the FCT for a $\mathrm{PhD}$ grant (SFRH/BD/17852/2004).

\section{REFERENCES}

1 Seixas de Melo J, Costa T, Miguel MG, Lindman B and Schillén K, F Phys Chem B 107:12605 (2003).

2 Anghel DF, Toca-Herrera JL, Winnik FM, Rettig W and von Klitzing R, Langmuir 18:5600 (2002).

3 Anghel DF, Alderson V, Winnik FM, Mizusaki M and Morishima Y, Polymer 39:3035 (1998).

4 Costa T, Miguel MG, Lindman B, Schillén K, Lima JC and Seixas de Melo J, $\mathcal{F}$ Phys Chem B 109:3243 (2005).

5 Costa T, Miguel MG, Lindman B, Schillén K and Seixas de Melo JS, f Phys Chem B 109:11478 (2005).

6 Connors KA, Chem Rev 97:1325 (1997).

7 Werner TC, Colwell K, Agbaria RA and Warner IM, Appl Spectrosc 50:511 (1996).

8 Szejtli J, Chem Rev 98:1743 (1998).

9 Crane NJ, Mayrhofer RC, Betts TA and Baker GA, 7 Chem Ed 79:1261 (2002).

10 Yorozu T, Hoshino M and Imamura M, f Phys Chem 86:4426 (1982).

11 Nelson G, Patonay G and Warner IM, Anal Chem 60:274 (1988).

12 Nelson G, Patonay G and Warner IM, Talanta 36:199 (1989).

13 Kusumoto Y, Chem Phys Lett 136:535 (1987).

14 Kano K, Matsumoto H, Yoshimura Y and Hashimoto S, $\mathcal{F}$ Am Chem Soc 110:204 (1988).

15 Haldar B, Mallick A, Purkayastha P, Burrows HD and Chattopadhyay $\mathrm{N}$, Indian $\mathcal{f}$ Chem A: Inorg Bio-Inorg Phys Theor Anal Chem 43:2265 (2004).

16 Du XZ, Zhang Y, Huang XZ, Li YQ, Jiang YB and Chen GZ, Spectrochim Acta A 52:1541 (1996).

17 Braga SS, Goncalves IS, Lopes AD, Pillinger M, Rocha J, Romao CC, et al, f Chem Soc Dalton Trans 2964 (2000).

18 Cunha-Silva L, Goncalves IS, Pillinger M, Xue WM, Rocha J, Teixeira-Dias JJC, et al, 7 Organometall Chem 656:281 (2002). 
19 Braga SS, Ribeiro-Claro P, Pillinger M, Goncalves IS, Pereira F, Fernandes AC, et al, Org Biomolec Chem 1:873 (2003).

20 Braga SS, Goncalves IS, Herdtweck E and Teixeira-Dias JJC, New f Chem 27:597 (2003).

21 Werner TC, Forrestall KJ, McIntosh SL and Pitha J, Appl Spectrosc 54:560 (2000).

22 Sandier A, Brown W, Mays H and Amiel C, Langmuir 16:1634 (2000).

23 Hollas M, Chung M-A and Adams J, F Phys Chem B 102:2947 (1998).

24 Karlson L, Thuresson K and Lindman B, Langmuir 18:9028 (2002).

25 Schillen K, Anghel DF, Miguel MD and Lindman B, Langmuir 16:10528 (2000)

26 Seixas de Melo J, Chem Educator 10:26 (2005).

27 Seixas de Melo J, Silva LM and Kuroda M, $\mathcal{f}$ Chem Phys 115:5625 (2001).

28 Stricker G, Subramaniam V, Seidel CAM and Volkmer A, F Phys Chem B 103:8612 (1999).

29 Schillén K, Anghel DF, Miguel MD and Lindman B, Langmuir 16:10528 (2000)

30 Gonzalez C and Lim EC, $\mathcal{F}$ Phys Chem A 104:2953 (2000).

31 Seixas de Melo J, Francisco A, Costa T, Maçanita A, Gago S and Gonçalves IS, Phys Chem Chem Phys DOI: 10.1039/ B613382G (2007).

32 Zachariasse KA, Duveneck G and Kuhnle W, Chem Phys Lett 113:337 (1985).

33 Tsuchida A, Ikawa T, Tomie T and Yamamoto M, f Phys Chem 99:8196 (1995).

34 Ilharco LM and Martinho JMG, Langmuir 15:7490 (1999).

35 Winnik FM, Chem Rev 93:587 (1993).

36 Winnik MA, Bystryak SM, Liu ZQ and Siddiqui J, Macromolecules 31:6855 (1998).

37 Ezzell SA, Hoyle CE, Creed D and McCormick CL, Macromolecules 25:1887 (1992).

38 Dong DC and Winnik MA, Can $\mathcal{f}$ Chem Rev Canadienne Chim 62:2560 (1984).

39 Karpovich DS and Blanchard GJ, f Phys Chem 99:3951 (1995).

40 Miguel MD, Adv Colloid Interf Sci 89:1 (2001).

41 Winnik FM, Winnik MA, Ringsdorf $\mathrm{H}$ and Venzmer J, $\mathcal{f}$ Phys Chem 95:2583 (1991)

42 Street KW and Acree WE, Analyst 111:1197 (1986).

43 Castanheira EMS, Martinho JMG, Duracher D, Charreyre MT, Elaissari A and Pichot C, Langmuir 15:6712 (1999).

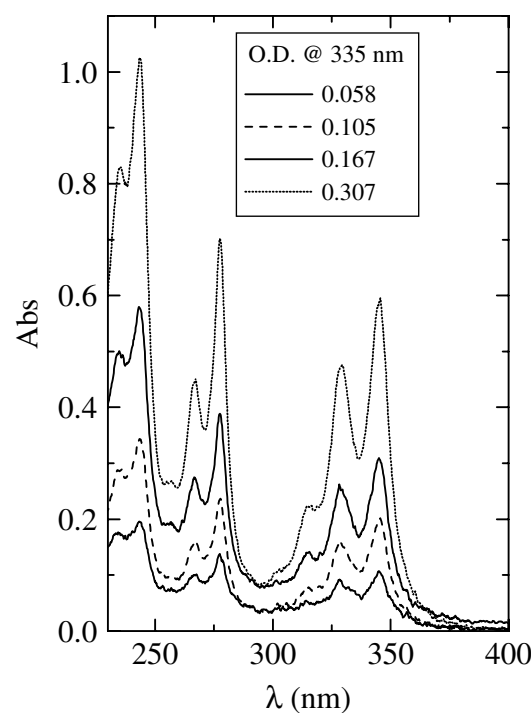

44 Valeur B, in Molecular Luminescence Spectroscopy. Methods and Applications: Part 3, vol. 77, ed. by Schulman SG. WileyInterscience, New York (1993).

45 Kalyanasundaram K and Thomas JK, $\mathcal{F}$ Phys Chem 81:2176 (1977).

46 Kalyanasundaram K and Thomas JK, f Am Chem Soc 99:2039 (1977).

47 Seixas de Melo J, Francisco A, Costa T, Gago S and Gonçalves IS, in Coloides e Interfases, vol. 88, ed. by Moreno MDM. Ediciones Universidad Salamanca, Salamanca, p. 291 (2005)

48 Brouwer F, in Conformational Analysis of Molecules in Excited States, ed. by Waluk J. Wiley-VCH, New York, p. 177 (2000).

49 Turro N, Modern Molecular Photochemistry. University Science Books, Sausalito, CA (1991).

50 Birks JB, Photophysics of Aromatic Molecules. Wiley, London (1970).

51 Seixas de Melo J and Maçanita AL, Chem Phys Lett 204:556 (1993).

52 Zachariasse KA and Striker G, Chem Phys Lett 145:251 (1988).

53 Zachariasse KA, Busse R, Duveneck G and Kuhnle W, f Photochem 28:237 (1985).

\section{APPENDIX A: SUPPLEMENTARY INFORMATION}

Figure A1 shows the absorption and emission spectra of the PAAMePy55 polymer obtained with four different concentrations (the optical densities at the excitation wavelengths vary from a ratio of $\sim 5$ ) and for acidic $(\mathrm{pH} \approx 3.5)$ media together with the resultant $I_{\mathrm{E}} / I_{\mathrm{M}}$. This $I_{\mathrm{E}} / I_{\mathrm{M}}$ displays, within the experimental error, the same values independently of the solution concentration of the polymer. The data reveal the occurrence of pure intramolecular interactions (see text for more details).

\section{Time-dependent aspects}

The differential equations controlling the timedependent concentration of the four excited species

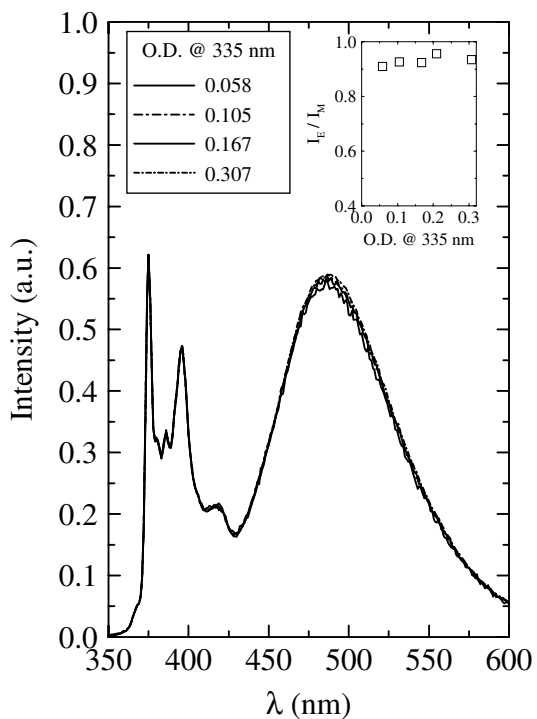

Figure A1. Absorption (left hand panel) and fluorescence (right hand panel) spectra, normalized at the monomer emission maxima, for the PAAMePy55 polymer (at various concentrations) at $\mathrm{pH}=3.5, T=293 \mathrm{~K}$. The inset shows the $I_{\mathrm{E}} / I_{\mathrm{M}}$ ratio versus the optical density at $335 \mathrm{~nm}$. The constancy of this ratio indicates the presence of intrapolymeric interactions. 

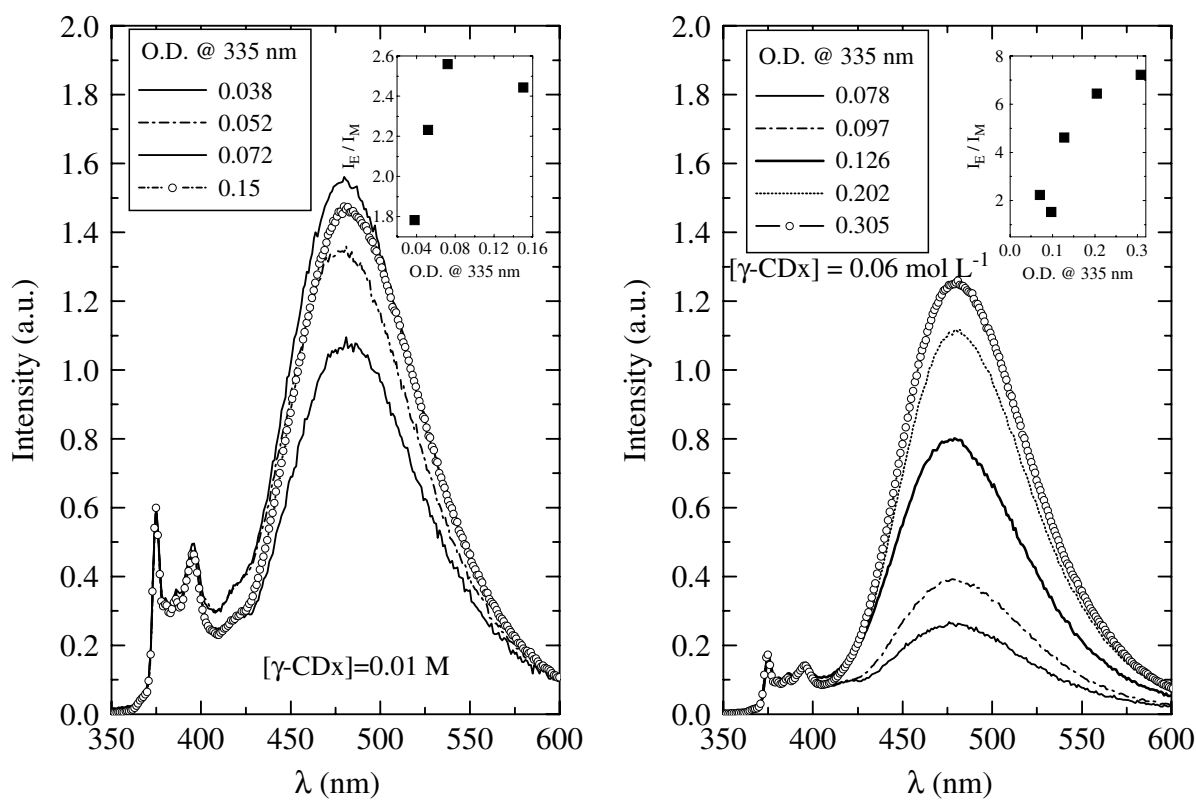

Figure A2. Fluorescence spectra, normalized at the monomer emission maxima, for the PAAMePy55 polymer (at various concentrations) and at two $\gamma$-CD concentrations at $\mathrm{pH}=3.5, T=293 \mathrm{~K}$. This is analogous to Fig. A1 but with the addition of $\gamma$-CD.
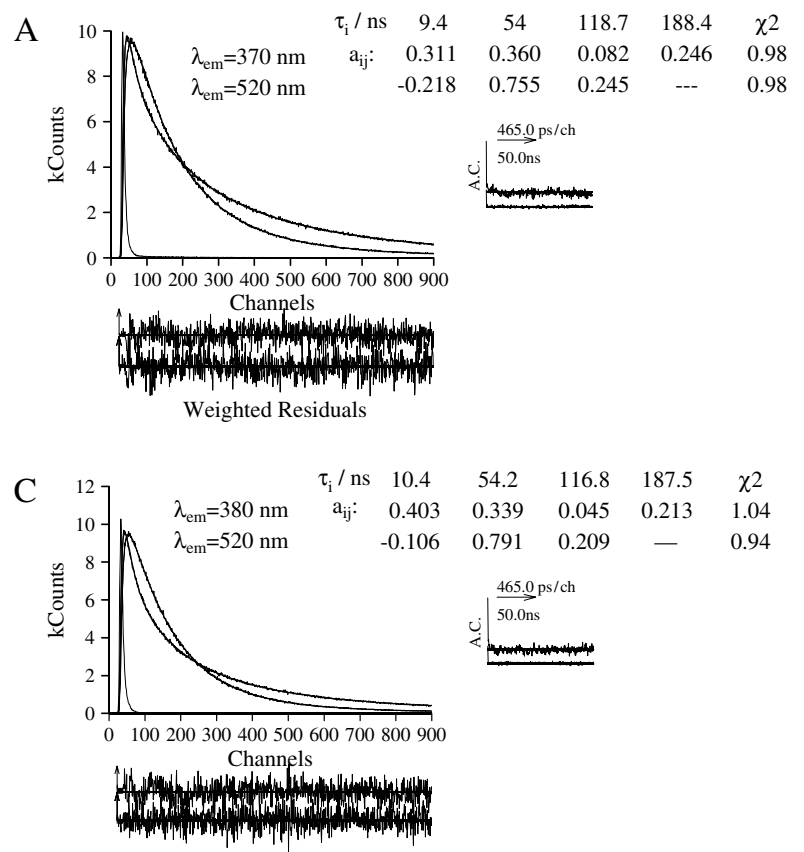

Weighted Residuals

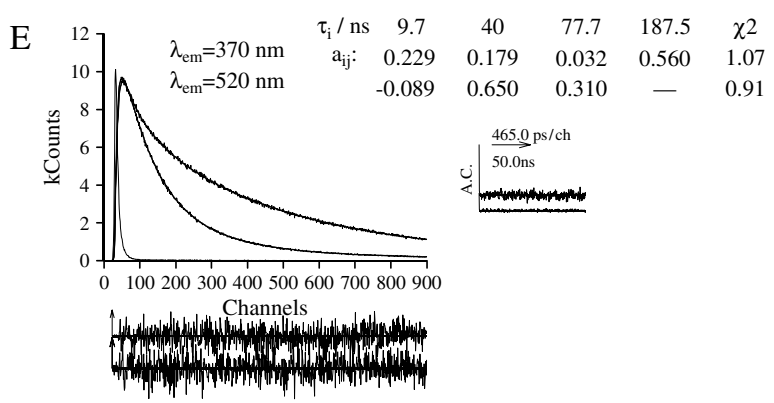

Weighted Residuals

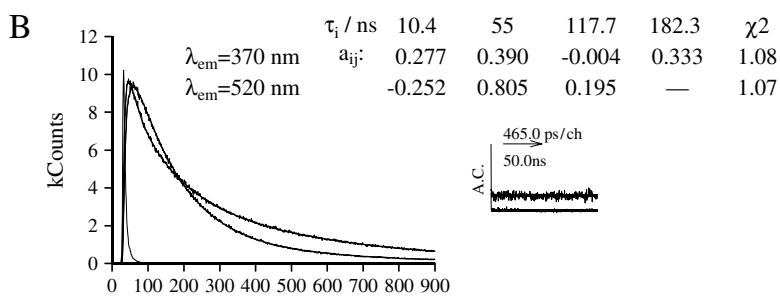

Channels

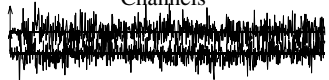

Weighted Residuals

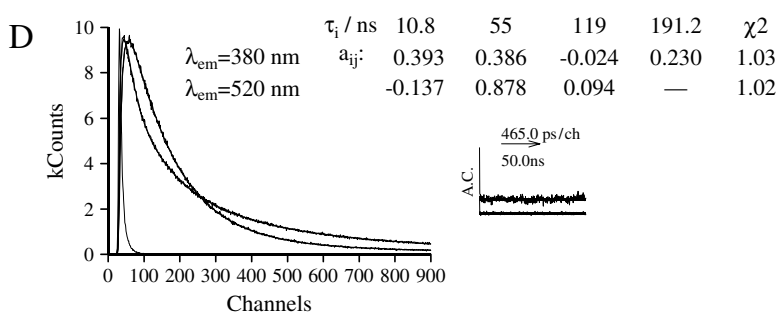

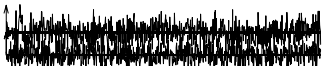

Weighted Residuals

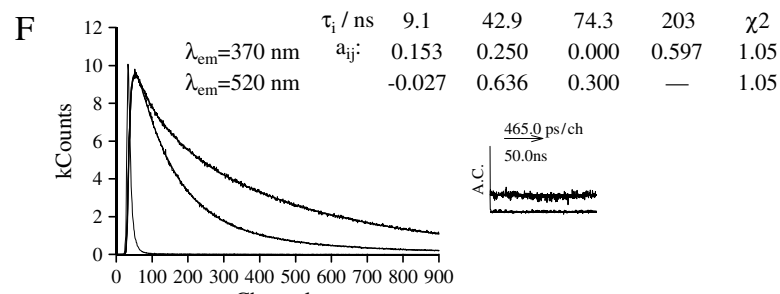

Channels

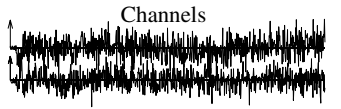

Weighted Residuals

Figure A3. Fluorescence decays for PAAMePy55 obtained with global analysis (simultaneous analysis) at $\mathrm{pH} \approx 3$, with $(\mathrm{A})[\beta-\mathrm{CD}]=0.002 \mathrm{~mol} \mathrm{~L}^{-1}$ and $\lambda_{\text {exc }}=315 \mathrm{~nm}$, (B) $[\beta-C D]=0.006 \mathrm{~mol} \mathrm{~L}^{-1}$ and $\lambda_{\text {exc }}=315 \mathrm{~nm}$, (C) $[\beta-C D]=0.002 \mathrm{~mol} \mathrm{~L}^{-1}$ and $\lambda_{\text {exc }}=350 \mathrm{~nm}$, (D) $[\beta-C D]=0.006 \mathrm{~mol} \mathrm{~L}^{-1}$ and $\lambda_{\text {exc }}=350 \mathrm{~nm}$. (E, F) PAAMePy55 at pH $\approx 8$ with $\lambda_{\text {exc }}=335 \mathrm{~nm}$ : $(\mathrm{E})[\beta-\mathrm{CD}]=0.001 \mathrm{~mol} \mathrm{~L}^{-1}$ and $(\mathrm{F})[\beta-\mathrm{CD}]=0.008 \mathrm{~mol} \mathrm{~L}^{-1}$. Also shown are the weighted residuals, autocorrelation functions $(\mathrm{AC})$ and the chi-square values $\left(\chi^{2}\right)$, for a better judgment of the quality of the fits. 

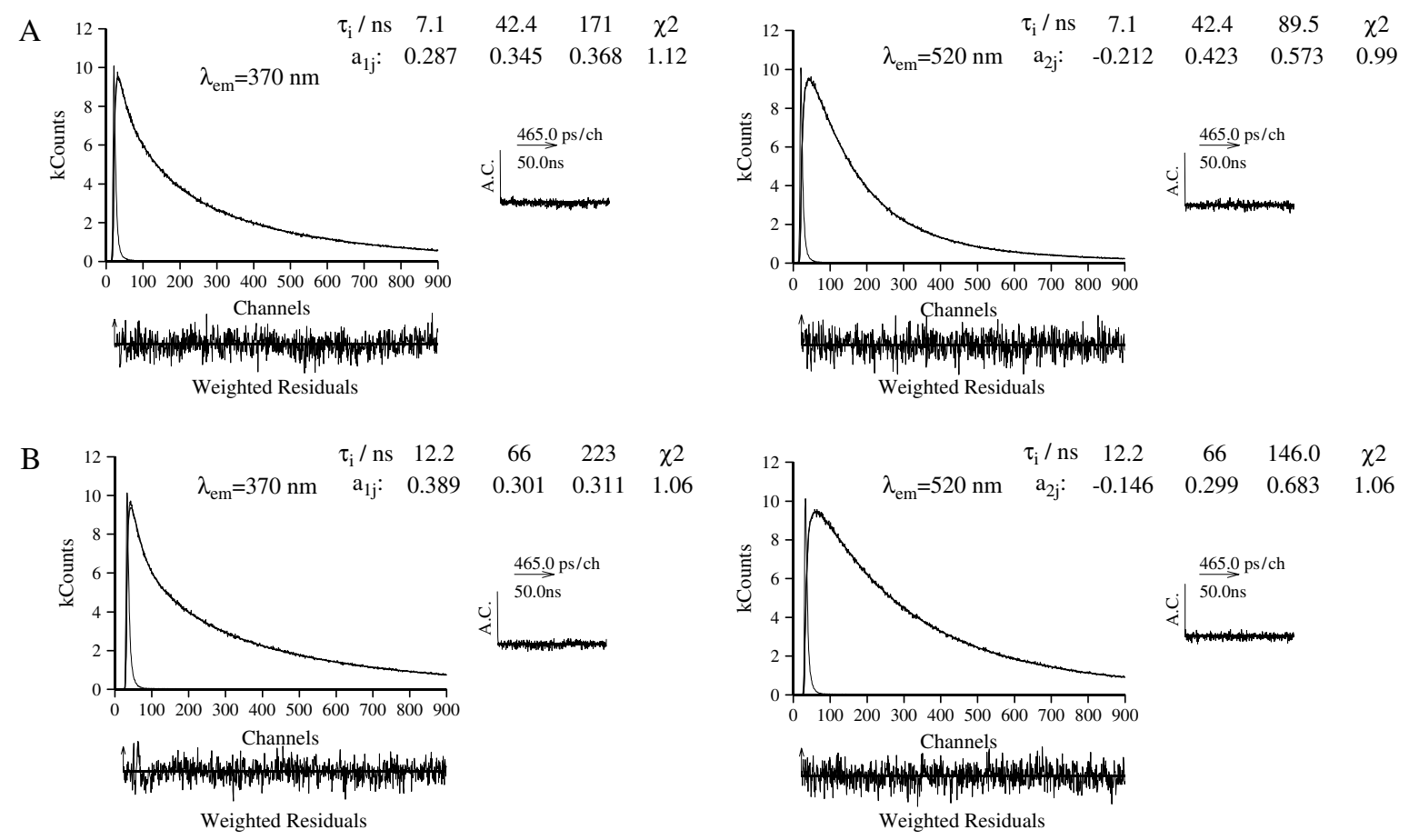

Figure A4. Fluorescence decays for PAAMePy55 obtained with individual analysis at $\mathrm{pH} \approx 3$ and $\lambda_{\text {exc }}=315 \mathrm{~nm}$, with $(\mathrm{A})[\gamma-\mathrm{CD}]=0.002 \mathrm{~mol} \mathrm{~L}^{-1}$ and $(B)[\gamma-C D]=0.050 \mathrm{~mol} \mathrm{~L}^{-1}$. Also shown are the weighted residuals, autocorrelation functions $(A C)$ and the chi-square values $\left(\chi^{2}\right)$, for a better judgment of the quality of the fits.

are, according to Scheme 3, given by

$$
\frac{\mathrm{d}}{\mathrm{d} t}\left[\begin{array}{c}
M_{\mathrm{A}}^{*} \\
M_{\mathrm{B}}^{*} \\
E_{1}^{*} \\
E_{2}^{*}
\end{array}\right]=\left[\begin{array}{cccc}
-k_{M} & 0 & 0 & 0 \\
0 & -k_{X} & k_{d_{1}} & k_{d_{2}} \\
0 & k_{a_{1}} & -k_{Y} & 0 \\
0 & k_{a_{2}} & 0 & -k_{Z}
\end{array}\right] \cdot\left[\begin{array}{c}
M_{\mathrm{A}}^{*} \\
M_{\mathrm{B}}^{*} \\
E_{1}^{*} \\
E_{2}^{*}
\end{array}\right]
$$

where $M_{\mathrm{A}}{ }^{*}, M_{\mathrm{B}}{ }^{*}, E_{1}{ }^{*}$ and $E_{2}{ }^{*}$ are the concentrations of $M_{A}, M_{B}, E_{1}$ and $E_{2}$ in the excited state and

$$
\begin{aligned}
& k_{X}=k_{M}+k_{a_{1}}+k_{a_{2}} \\
& k_{Y}=k_{E_{1}}+k_{d_{1}} \\
& k_{Z}=k_{E_{2}}+k_{d_{2}}
\end{aligned}
$$

After matrix factorization, a $3 \times 3$ matrix of rate constants $\left[k_{i, j}\right]$ is obtained which could then be evaluated from ${ }^{51}$

$$
\begin{aligned}
k_{i, j} & =\left[\begin{array}{ccc}
-k_{X} & k_{d_{1}} & k_{d_{2}} \\
k_{a_{1}} & -k_{Y} & 0 \\
k_{a_{2}} & 0 & -k_{Z}
\end{array}\right] \\
& =\left[A_{i j}\right] \times\left[-\lambda_{i, j}\right] \times\left[A_{i, j}\right]^{-1}
\end{aligned}
$$

In order to solve properly Eqn (A5) an additional emission wavelength is needed. Indeed since three coupled species are involved in Scheme 3 the only way to solve Eqn (A3) is to know the amplitude factors at three emission wavelengths. However, as can be observed from Figs 10 and 11 we have only obtained the decays at two emission wavelengths and thus an additional emission wavelength must be considered. This was considered elsewhere ${ }^{2}$ but is beyond the objectives of the present work. Moreover the data that are provided by the fluorescence decays are not sufficient for solving Eqn (A5). Although there are only 6 unknown rate constants $\left(k_{M}\right.$ is equal to the reciprocal longest decay time $\tau_{0} \equiv \tau_{M}$ ), the preexponential coefficients matrix $\left[A_{i j}\right]$ must be evaluated from the experimental pre-exponential coefficients and five additional unknowns: the 3 fractions of groundstate species ( $\alpha, \beta$ and $\gamma$ ), plus the two spectral overlapping factors at the two excimer emission wavelengths. This is an ongoing study which is currently in progress.

Figure A3 shows the fluorescence decays of PAAMePy55 in the presence of different concentrations of $\beta$-CD, obtained with different excitation wavelengths and two different $\mathrm{pH}$ values.

As mentioned in the text, if we compare Fig. A3(A) with Fig. A3(C) and Fig. A3(B) with Fig. A3(D), it is observed that the negative amplitude value - preexponential factor $\left(a_{22}\right)$ - becomes progressively less negative with increasing excitation wavelength. 